ORNL/TM-2000/41

ENERGY DIVISION

\title{
REVIEW OF THE STRUCTURE OF BULK POWER MARKETS GRID OF THE FUTURE WHITE PAPER
}

\author{
BRENDAN KIRBY and JOHN KUECK
}

\author{
January 2000 \\ Sponsored by \\ Consortium for Electric Reliability Technology Solutions \\ U.S. Department of Energy \\ Washington, DC 20585
}

OAK RIDGE NATIONAL LABORATORY

Oak Ridge, Tennessee 37831 managed by

LOCKHEED MARTIN ENERGY RESEARCH CORPORATION

for the

U.S. DEPARTMENT OF ENERGY

under contract No. DE-AC05-96OR22464 


\section{CONTENTS}

Page

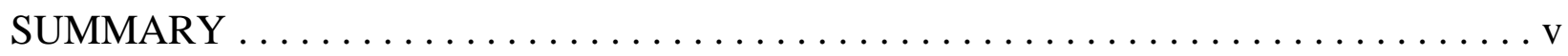

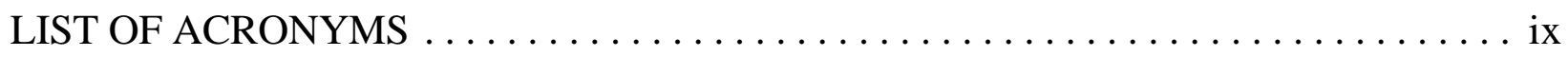

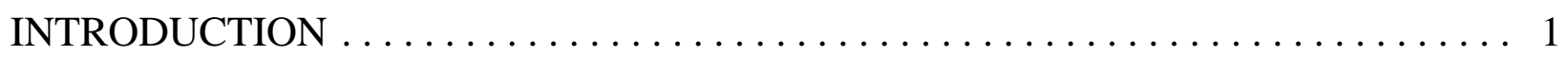

SYSTEM PLANNING, CONSTRAINED ECONOMIC DISPATCH, AND INTER

UTILITY TRANSACTIONS - THE HISTORIC FRAMEWORK $\ldots \ldots \ldots \ldots .3$

THE OBJECTIVE OF RESTRUCTURING $\ldots \ldots \ldots \ldots \ldots \ldots \ldots \ldots \ldots \ldots$

RELIABILITY IS COMPOSED OF ADEQUACY AND SECURITY $\ldots \ldots \ldots .7$

INCENTIVES FOR TRANSMISSION EXPANSION $\ldots \ldots \ldots \ldots \ldots \ldots \ldots 10$

RESPONSIBILITIES OF AN ISO VS AN RTO $\ldots \ldots \ldots \ldots \ldots \ldots \ldots \ldots 11$

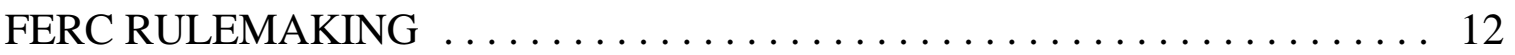

ALTERNATIVE MARKET STRUCTURES . . . . . . . . . . . . . . . . 13

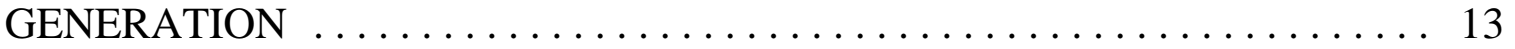

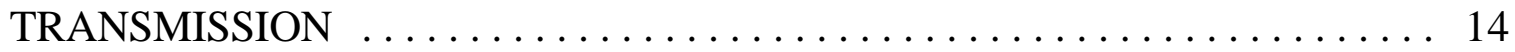

TCCs AND TRANSMISSION INVESTMENT $\ldots \ldots \ldots \ldots \ldots \ldots \ldots \ldots$

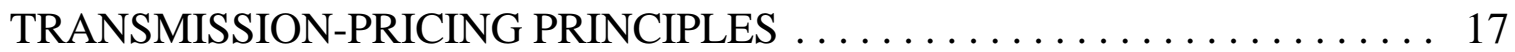

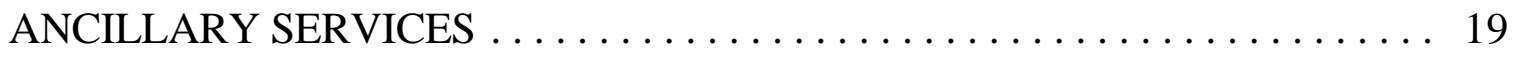

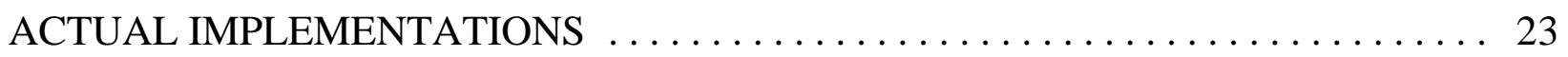

CALIFORNIA IMPLEMENTATION OF BULK POWER MARKET $\ldots \ldots \ldots 23$

PJM IMPLEMENTATION OF BULK POWER MARKET . . . . . . . . . 30

ISO NEW ENGLAND IMPLEMENTATION OF BULK POWER MARKET . . 34

UNITED KINGDOM IMPLEMENTATION OF BULK POWER MARKET . . . 37

IMPLEMENTATION OF ALBERTA BULK POWER MARKET . . . . . . . . . 42

IMPLEMENTATION OF THE AUSTRALIAN BULK POWER MARKET . . . . 44

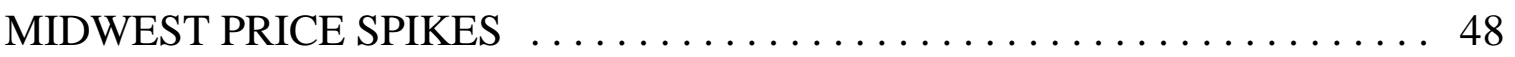

LOAD AS A BULK POWER SYSTEM

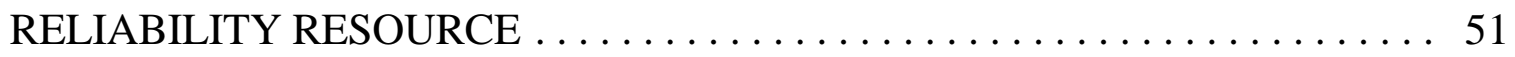




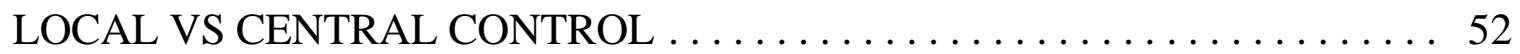

LOAD ECONOMIC DECISION PROCESS $\ldots \ldots \ldots \ldots \ldots \ldots \ldots \ldots \ldots . \ldots$

MARKETS LOADS MAY WANT TO PARTICIPATE IN $\ldots \ldots \ldots \ldots \ldots 55$

CERTIFICATION AND AGGREGATION $\ldots \ldots \ldots \ldots \ldots \ldots \ldots \ldots \ldots . \ldots \ldots$

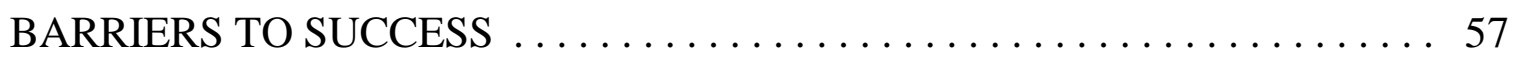

SPECIAL R\&D NEEDS TO FACILITATE RELIABILITY

AND BULK POWER MARKETS $\ldots \ldots \ldots \ldots \ldots \ldots \ldots \ldots \ldots \ldots \ldots$

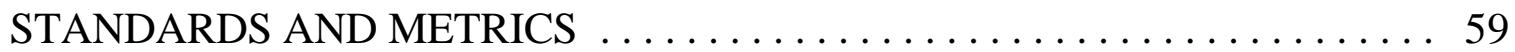

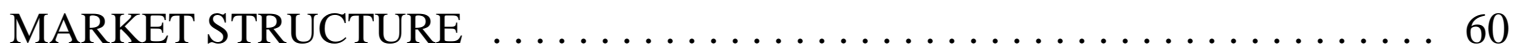

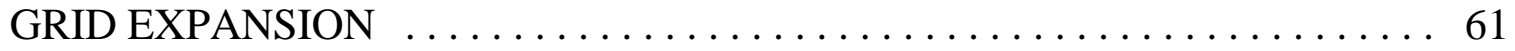

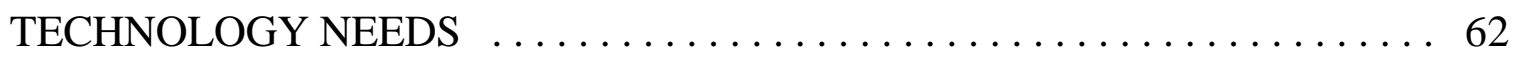

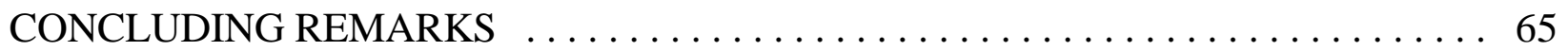




\section{SUMMARY}

Historically, the bulk power market structure was dominated by vertically integrated utilities granted monopoly franchise service territories. Performance, both economic and reliability, was judged in a holistic fashion by regulators who approved tariffs that customers were obligated to pay. Restructuring seeks to introduce competition into electric power markets in order to improve economic efficiency. The impact of these changes on reliability is the subject of this report.

Restructuring is not changing the physical needs of the power system. The functions previously performed by the vertically integrated utility must be accommodated by the new market structure. These functions range from assuring an adequate electricity supply through multi-year planning of the generation and transmission system, to meeting shorter term forecasted load by deploying existing resources through unit commitment, to assuring system security through automatic generation control, and operating the transmission system by controlling ancillary services such as reserves and blackstart capability.

The controller of the physical system, of necessity, has control of the commercial transactions; no generator or load can interact with electricity markets unless the system operator facilitates that interaction. Consequently, a basic feature of the restructured industry is that the system operator must be isolated from commercial market pressures. At a minimum, a "code of conduct" is required that prevents the system operator from providing preferential treatment for generation or transactions that are owned or sponsored by the system operators company. At a maximum, the system operator can be an independent, non-profit, commercial organization, an Independent System Operator (ISO).

Six restructured market systems were reviewed for this report: California; Pennsylvania, New Jersey, Maryland (PJM); New England; United Kingdom; Alberta; and Australia. Summaries of these new market systems are as follows:

In California, two new market entities have been created: a "Power Exchange" or wholesale market for power, and a separate ancillary services market conducted by the ISO. Both markets have been experiencing problems such as apparent market power and too few bids for some ancillary services. The grid is experiencing congestion in some areas, and in some cases large generators take advantage of congestion rules. The ISO has instituted several "fixes" to deal with these problems and has obtained FERC orders in some instances, but there are still opportunities that continue to be available for players to "game" the system. 
The PJM market has made a transition from a zonal to a nodal system where spot prices are calculated for some 2,000 nodes. When the system is congested, these prices may diverge. This divergence allows traders to "buy through" congestion. Another market feature allows traders to collect "rent" on transmission lines as a hedge against congestion. During the heat storm this summer, rotating blackouts were required after a single contingency due to lack of generation in an area where nodal prices were not yet functioning. It is hoped that problems such as this will be addressed by the market process as the market matures and market driven new generation is constructed in the areas where it is most needed

In New England, new generators have much difficulty in gaining access to the grid apparently because of firmly entrenched market power. It seems likely that there will be a series of appeals to FERC to correct inequities. This process has already started. This will probably delay the maturing and efficient functioning of the market.

In the United Kingdom, a tremendously complex market has evolved. It appears this market provides ample opportunity for gaming because of its complexity and is being blamed for high electricity prices. As a solution, a Power Exchange and other changes are being developed. The target date for the changes to the existing system is slipping into the fall of 2,000.

The Alberta system has one zone for the entire pool area. A complex system of legislated hedges was put into place when the system was first implemented to put a damper on market power and to achieve economic goals. The planning process has also ensured that potential stranded assets are dealt with and costs are recovered. Transmission upgrades are needed because the bulk of the generation is in the North and the bulk of the load is in the South, however, upgrades to the North - South corridor will not be used if the market is effective in bringing new generation to the South.

Australia has a relatively simple system where ancillary services are contracted by the National Agency rather than made part of the market. Suppliers bid into a pool with an essentially real time market; suppliers may revise their offers until a short period of time before the real time energy auction. There is no day ahead market. The grid is divided into four zones and there is a method for calculating locational prices. The federal government has stringent codes on how the market is to be operated that apply uniformly across the nation. The market is working well in reducing costs, and there does not appear to be excessive market power or gaming. The ultimate plan is for all customers to have access to the wholesale market if they wish.

It is tempting to view the Midwest price spikes during the summers of 1998 and 1999 as reliability events. They certainly bear studying to understand what happened to drive prices to $\$ 7000$ and $\$ 9000 / \mathrm{MWH}$. Generation was nearly inadequate to serve unconstrained load, but it is not clear that security was threatened. In the sense that reliability is composed of adequacy (generation and transmission) and security, this was a reliability event. If the system 
operators were diligent in maintaining contingency reserves, if they resisted economic and political pressure to use contingency reserves to serve load and thereby left the system unable to deal with the next contingency, then security was not threatened. Some customers may have been curtailed involuntarily but the system security was not necessarily threatened. This is quite different from conditions in MAPP in June of 1997 when the system came close to collapse or WSCC in July and August of 1996 when the system actually did collapse.

The price spikes indicate a lack of adequate generation; the system collapses indicate an insecure system. Restructuring tries to address adequacy through markets. Clearly these are not fully functional markets when prices rise to 500 times their normal values and there is no demand elasticity. But this is an indication of market failure, not a technical failure of the power system. The simple expedient of allowing loads to participate in real-time energy markets would likely mitigate the price spikes.

Restructuring bulk power markets dramatically intensifies the need for federally sponsored research into electric system reliability. Private entities have greater incentive to perform research and develop products but only if the effort will result in profit exclusively for the investor. A competitive market participant cannot afford to invest in research that will benefit its competitors as well as itself. It is better off waiting for others to incur the expense. Technologies that increase the capacity of the community transmission system will only be developed through federally supported research. Similarly, technologies that assist the system operator in observing and controlling the power system will allow the system to provide greater throughput while maintaining reliability. These will only be developed through federally supported research. Federal support is needed to overcome the technical and institutional barriers that are preventing load from being used as a resource to support bulk power system reliability. This last area would likely provide the greatest, most immediate, return on investment.

Federally supported research is required to further the design of bulk power markets themselves. Metrics are needed to assess the overall performance of markets and allow different market structures to be compared. Computer based simulation and modeling is needed to analyze the expected behavior of markets, both for macroscopic behavior and to analyze the impact of specific rule changes. Markets are inherently human activities and interrelated energy and ancillary service markets are particularly complex ones. Modeling and computer simulation can only go so far. Experimental economics studies are required to extend the analysis of market designs that assure reliability.

Load control (and distributed generation) is an underutilized resource for addressing bulk power system reliability. At present, load is not responsive to the hourly price because it is denied access to real time markets. New communications, control and metering technology may make it possible for loads to sell ancillary services as well as participate in real-time energy markets. This could reduce the need for new generation and transmission, free 
generation to provide energy, greatly mitigate price spikes, and relieve transmission congestion. Technical and institutional obstacles must be overcome. Services must be defined in terms of actual requirements, not in terms of the central generation resources that have traditionally supplied them.

Near term, research is required to define ancillary service requirements and metrics. Work in this area is going extremely slowly, primarily because it is being performed on a voluntary basis by entities that perceive commercial benefit from participating. The basic problem is of competitive individuals being unable to invest in a community solution. Research is also needed in market technologies to enhance transmission capacity, planning tools and in market structures to ensure long term reliability. 


\section{LIST OF ACRONYMS}

$\begin{array}{ll}\text { ACE } & \text { Area Control Error } \\ \text { AGC } & \text { Automatic-Generation Control } \\ \text { A/S } & \text { Ancillary Services } \\ \text { CAISO } & \text { California Independent System Operator } \\ \text { decs } & \text { decrements } \\ \text { DGES } & \text { Director General of Electricity Supply } \\ \text { DISG } & \text { Development and Implementation Steering Group } \\ \text { DTI } & \text { Department of Trade and Industry } \\ \text { EMS } & \text { Energy Management System } \\ \text { ESBI } & \text { Electric Service Board International } \\ \text { FCRs } & \text { Financial Congestion Rights } \\ \text { FERC } & \text { Federal Energy Regulatory Commission } \\ \text { FTR } & \text { Fixed Transmission Right } \\ \text { GOAL } & \text { Generator Ordering and Loading } \\ \text { ISO } & \text { Independent System Operator } \\ \text { incs } & \text { increments } \\ \text { ITC } & \text { Independent Transmission Company } \\ \text { LOLP } & \text { Loss-of-Load Probability } \\ \text { LMP } & \text { Locational Marginal Price } \\ \text { LSE } & \text { Load-Serving Entity } \\ \text { MCP } & \text { Market Clearing Price } \\ \text { MDG } & \text { Market Design Group } \\ \text { MW } & \text { Megawatt } \\ \text { NEM } & \text { National Energy Market } \\ \text { NEMMCO } & \text { National Electricity Market Management Company NERC } \\ \text { NEPOOL } & \text { New England Power Pool } \\ \text { NGC } & \text { National Grid Company } \\ \text { NOPR } & \text { Notice of Proposed Rulemaking } \\ \text { NSW } & \text { New South Wales } \\ \text { NUG } & \text { Non-Utility Generator } \\ \text { OFFER } & \text { Office of Electricity Regulation } \\ \text { PJM } & \text { Pennsylvania, New Jersey, Maryland } \\ \text { PPP } & \text { Pool Purchase Price } \\ \text { PTO } & \text { Participating Transmission Owners } \\ \text { PUC } & \text { Public Utility Commission } \\ & \end{array}$




$\begin{array}{ll}\text { PX } & \text { Power Exchange } \\ \text { REPA } & \text { Regulation Energy Payment Adjustment } \\ \text { RMR } & \text { Reliability Must Run } \\ \text { RTEP } & \text { Regional Transmission Expansion Plan } \\ \text { RTO } & \text { Regional Transmission Organization } \\ \text { SC } & \text { Scheduling Coordinator } \\ \text { SCADA } & \text { Supervisory Control and Data Acquisition System } \\ \text { SERP } & \text { System Expansion Related Pricing } \\ \text { SIS } & \text { System Impact Study } \\ \text { SMP } & \text { System Marginal Price } \\ \text { SPD } & \text { Scheduling Pricing and Dispatch } \\ \text { TA } & \text { Transmission Administrator } \\ \text { TCC } & \text { Transmission-Congestion Contract } \\ \text { TLR } & \text { Transmission Loading Relief } \\ \text { UK } & \text { United Kingdom } \\ \text { VOLL } & \text { Value of Lost Load } \\ \text { WSCC } & \quad \text { Western States Coordinating Council }\end{array}$




\section{INTRODUCTION}

This paper is intended to provide an understanding of the needs of a restructured electricity market and some of the market methods and systems that have developed to address those needs.

Chapter 2 discusses the historic market framework of vertically integrated utilities.

Chapter 3 introduces the changes to the vertically integrated utility brought about by restructuring. It discusses generation and transmission planning, control and the regulatory process. It also summarizes reliability, security and adequacy.

Chapter 4 discusses the basic structures of generation and transmission markets along with transmission-congestion contracts (TCCs) and transmission pricing principles. A discussion is given of the 12 ancillary services needed to reliably operate the power system. Chapter 4 also deals with the role of transmission in opening up markets to competition. In California increments (incs) and decrements (decs) are bid to overcome price differences in different zones caused by congestion. In PJM, any member can purchase Fixed Transmission Rights (FTRs) which allows the member to "collect rent" on congested lines and essentially obtain a hedge against congestion. There has been a worrisome slowdown in the growth of the transmission system in the United States since about the mid 70's. However, there are methods for providing incentives for construction of new transmission using tariffs. The California and PJM transmission planning processes are outlined. The Federal Energy Regulatory Commission (FERC) has recently issued a proposed rulemaking on Regional Transmission Organizations (RTOs) which stated that the traditional methods of grid management are showing signs of strain and may be inadequate to support efficient and reliable transmission operations.

Chapter 5 provides examples of market implementations and a discussion of the price spikes seen in the Midwest in the summers of 1998 and 1999. An examination of six restructured market systems is performed in some detail. The systems are California, PJM (Pennsylvania, New Jersey, Maryland), New England, United Kingdom(UK), Alberta, and Australia. Finally, there is a discussion of the price spikes that occurred in the Midwest this summer from the viewpoint of market performance.

Chapter 6 deals with the concept of load as a resource. This is a novel idea that holds tremendous promise as technological advances permit real time control of loads based on the user's economic criteria. The user may be willing to curtail operations for some period of time 
when the spot price reaches a certain level, or the user may be willing to sell ancillary services to the system.

Chapter 7 outlines the research needs presented by a restructured industry and the vital federal role in meeting these needs. Without federal participation, research to advance the public good will not be performed by an industry now focused on profit.

Chapter 8 provides a summary and concluding remarks. 


\section{SYSTEM PLANNING, CONSTRAINED ECONOMIC DISPATCH, AND INTER UTILITY TRANSACTIONS - THE HISTORIC FRAMEWORK}

It is useful to briefly examine the historic framework of the vertically integrated utility to understand the functions that still must be performed after restructuring. The basic physical system is not changing. Restructuring is happening simultaneously with, but largely independent of, technological changes. Technological changes are making some aspects of restructuring possible but they do not compel it.

Electricity is a unique commodity in that storage is currently not practical, and supply and demand must be balanced in real time." The vertically integrated utility performed (and still performs in many locations) this balancing function in a number of time frames. A greatly simplified list includes:

\# Generation and Transmission Planning - Generation and transmission planning were coordinated and occurred 5 to 20 years in advance to assure that appropriate and sufficient resources were available to meet growing load.

\# $\quad$ Fuel Supply Procurement - Fuel supplies were centrally procured over one to several years.

\# Maintenance scheduling - Maintenance schedules for transmission and generation were coordinated over at least a year.

\# Unit Commitment - Generating units were committed to operate one day to one week ahead of actual need based upon short-term load forecasts.

\# Generator Control - Generators were controlled in real time to meet the energy requirements of the load including:

- Economic dispatch - For the supply of basic energy.

"Hydroelectric pumped storage is used successfully in a number of locations. These plants are generally large (several hundred MW), operate as central generation stations, and the number of attractive locations are limited. Storage on the customer side is under development but not yet commercially competitive. 
- Regulation and load following - To compensate for normal fluctuations.

- Contingency response - To correct for abnormal events.

All of this was centrally coordinated to meet the overall system requirements at the lowest total cost consistent with required reliability. Each utility was granted a franchise service territory, performance was judged by the state regulator. Eminent domain authority derived from the regulated franchise. The regulator motivated the utility by controlling the tariff and usually tied this to the rate of return on investment. Utilities interconnected their transmission systems in order to enhance reliability by sharing reliability reserves. They also used transmission interconnections for economic interchange when power costs in adjacent utilities differed.

One advantage of this regulatory structure was that explicit metrics were not strictly required. There was always sufficient judgement involved in the regulatory process that the utility knew it had to manage overall performance to the regulator's satisfaction. The regulatory process also protected the utility from investment risk. Once a transmission or generation facility plan was accepted by the regulator it was placed in the rate base and the customers were obligated to pay for it. The control the regulator had over rates and enhancement plans gave the regulator the primary role in determining the reliability goals of the system.

In response to the Northeast blackout, utilities collaborated to form the North American Electric Reliability Council (NERC) and regional reliability councils. These organizations developed guidelines to help further reliability objectives. The fundamental responsibility for reliability still remained with the individual vertically integrated utility and the regulator, however.

Generation should transition fairly easily into a market-based system, with several options on how it is structured. Taken to the logical conclusion, there is a fundamental shift as the regulated utility's "obligation to serve" becomes an "obligation to connect" under market conditions. Adequacy, assuring that there is sufficient generation available to serve the load, becomes a market function as it is in other industries. Customers assume the burden of obtaining the level of adequacy they require. They can either enter into long term contracts with suppliers or rely on shorter-term commodity markets for energy. Generators themselves can assume the responsibility (and associated financial risk) of performing the unit commitment function and deciding when to turn on and off.

In the other extreme, open markets for generation can be accommodated without forcing (or allowing) customers to assume the responsibility of assuring the adequacy of their own generation supply by having the ISO (or other independent organization) forecast requirements and operate a market to procure those resources. The ISO can enter into long 
term contracts providing capacity reserve margins. Customers can be forced to purchase their required power from the ISO's pool to ensure that the ISO is compensated for these long-term reserve contracts. Mixtures of the two structures described can also be created. Power pools can exist along side bilateral transactions. 


\section{THE OBJECTIVE OF RESTRUCTURING}

The fundamental goal of restructuring is to replace the highly regulated, vertically integrated, centrally optimized and controlled system with one that is primarily market based. The motivation is to lower prices and provide customer choice. Active markets for bulk electric power developed on their own accord among vertically integrated utilities. The first major shift opening these markets to others came when the Public Utility Regulatory Policy act of 1978 allowed Non-Utility Generators (NUGs) to participate in the supply of electricity, though the process was highly regulated. The FERC Orders 888 and 889 took the major step of mandating open access for the transmission system thereby opening wholesale electricity markets to competition.

\section{RELIABILITY IS COMPOSED OF ADEQUACY AND SECURITY}

Changing from a structure where a regulator approves capital expenditures and judges system reliability to a structure dominated by markets changes how reliability is addressed. NERC defines reliability as "the degree to which the performance of the elements of [the electrical] system results in power being delivered to consumers within accepted standards and in the amount desired." NERC's definition of reliability encompasses two concepts: adequacy and security. Adequacy is defined as "the ability of the system to supply the aggregate electric power and energy requirements of the consumers at all times." Security is "the ability of the system to withstand sudden disturbances."

In plain language, adequacy deals with planning and investment, and security deals with short-term operations. Adequacy implies that there are sufficient generation and transmission resources available to meet projected needs plus reserves for contingencies. Security implies that the system will remain intact even after outages or other equipment failures occur. Although adequacy is a reliability concept, it has strong commercial implications; the same is true of security. Indeed, although we might like to pretend otherwise, bulk-power reliability and commerce are strongly interdependent.

Obviously, adequacy and security are complements. Without system security, the output of the generation resources, no matter how abundant, cannot be delivered to customers. Correspondingly, a high degree of security is of little value if there are insufficient generation and transmission resources to meet customer needs. 
The substitution nature of adequacy and security is not so obvious. What we mean here is that more of one can make up for less of the other. For example, an abundance of generation and transmission resources makes it easier to maintain a high degree of security (i.e., reduces the need for emergency actions). That is, system operators can manage the system in real time with less data and fewer analytical tools if there are ample generation resources and redundant transmission facilities. Similarly, high-quality system operation can extract more output from a system that might otherwise be considered under built. For example, the near-real-time collection and analysis of data on the current and projected states of the transmission system can allow system operators to run the system closer to its limits than would less data collection and analysis.

In most industries adequacy is a market function. Each customer is free to contract in whatever fashion it feels is necessary to assure that the supply of the commodity it is purchasing is adequate. While there are some technical difficulties bringing this concept to the electric power industry (it can be difficult to associate individual suppliers with individual loads in real-time) it is also a conceptual problem for some. The idea of disconnecting customers because they failed to secure an adequate supply of electricity and the market finds itself short is so onerous to some that they force participation in future capacity markets." Unfortunately this disrupts the operations of real-time markets for energy and ancillary services. Forcing capacity on markets never lets them value capacity appropriately, capacity never becomes scarce. This has the apparent benefit of reducing price volatility in the energy and ancillary service markets. Unfortunately it also distorts the market solution and favors low capital cost, high operating cost generation.

Security likely will remain a regulated function for the foreseeable future because of the short time frame involved and the inability to isolate consequences to the individuals that caused them. Markets can be used to procure the security related ancillary services, however. Markets can also be used to allocate the costs of those services based upon consumption.

While the collection of ancillary services is designed to be comprehensive and mutually exclusive, markets for each and the market for basic energy heavily interact. Resources capable of providing one service can generally provide other services. Design of the overall market and the specific market rules becomes critical to maintaining economic efficiency and reliability. One advantage of the vertically integrated utility structure was that the regulator could hold the utility to an ill-defined requirement to maintain "reasonable" costs and "adequate" reliability by controlling the rate-of-return. With a rule-based market, on the other hand, individual participants will provide exactly the services specified in whatever proportion maximizes the individual's ability to profit.

*The New England market currently operates this way. 
Transmission plays a key role in opening markets to competition. Transmission system expansion, however, has not kept up with growth in the energy market, and some of the developing organizational changes really seem to do no more than better manage existing assets. A stronger transmission system would not only bring in competitive bidders from far away, but would also eliminate market pockets where existing large generators can exercise market power. At present in the United States, the transmission entities are not permitted to share in the benefits that would accrue to consumers from greater competition that stems from transmission expansion. Instead, transmission entities are concentrating on managing the congestion. ISO's have no commercial incentive to expand their systems. "When the United Kingdom restructured, it chose a for profit, regulated, Independent Transmission Company (ITC) - the National Grid Company (NGC) - to operate its electric power system. There have been very few problems with transmission congestion; the system is a tight, well-connected system so that there were few problems originally. Throughout the trials and difficulties that the restructured system has been going through in the UK, as discussed in Chapter 5, the NGC has performed fairly well and is economically quite sound.

A strong transmission system is one which rarely becomes congested. When a transmission system becomes congested, power prices tend to vary across the system because it is now impossible to supply low cost generation to every part of the system. Modern, computer based calculation methods now allow a system to be evaluated using a system of nodes, and a power price can be calculated for each node when congestion occurs. A system calculation may have literally thousands of nodes. This is the way prices are calculated across the PJM system now, a very tightly connected system across a relatively small geographic area. In a de-centralized system, such as the California ISO, it may be more appropriate to divide the system into a few zones, and calculate prices for each zone.

In a de-centralized system with only a few zones, such as California, the market relies on incs and decs to alleviate congestion. As a simplification, suppose there is congestion on lines from an exporting zone to an importing zone. Clearing the energy market price would result in a single price, the "uncongested price," and a flow exceeding transmission capacity. The remedy in Scandinavia's NordPool is to raise the price in the importing zone and reduce the price in the exporting zone until the net flow matches capacity; the difference between these two zonal prices is the usage fee charged for flows from the exporting zone to the importing zone, and equal credit is given for counter flows. This illustrates the general principles that transmission demands are derived from energy demands and supplies, and like reserves, congestion may be managed by amending the forward market for energy. California's market is similar, but it allows bidders to submit incs and decs to the transmission market that differ from their bids in the previous energy market. Sometimes the ISO receives insufficient offers to alleviate August 1999.

*"Transmission, Congestion, Pricing and Incentives," L. S. Hyman, IEEE Power Engineering Review, 
congestion and the market fails to clear, in which case a default usage fee is imposed. The default fee is partly punitive, but also it is intended to cover the ISO's expected costs of fixing the problem in real time using incs and decs in the spot market or using reserves.*

Zonal pricing in a decentralized system like California provides the potential for gaming. For example, a supplier who anticipates intrazonal congestion can sell a large quantity of power in the day ahead market at the clearing price knowing that the ISO will have to invoke the dec the next day. The supplier then submits a price for the dec that is lower than the clearing price, so the supplier collects a profit on the extra quantity he knew he would not have to produce. We understand that this sort of gaming has indeed been taking place in California.

Both the zonal and nodal systems offer firm rights to transmission access like those sold by gas pipeline companies. PJM calls these FTRs. Purchasing an FTR is like purchasing a reservation on a transmission line with a specified injection point and withdrawal point. An FTR allows energy traders to purchase protection from transmission congestion charges on a specific transmission path. The FTR owner receives congestion credits when the system becomes congested; in a sense, he is receiving rent on congestion charges. Any PJM member can purchase an FTR. In California, each right pertains to the interface between zones.

\section{INCENTIVES FOR TRANSMISSION EXPANSION}

From the mid-1970's until now the United State's transmission system has grown at less than half the pace of demand. The slowdown has coincided with a precipitous fall in generation reserve margins. Not only have high voltage transmission lines become nearly impossible to build in some geographic areas, but a utility that invests in new transmission exposes itself to large regulatory risks and will only earn a minimal regulated return on the investment. In addition, utilities do not know the rules that will be in place over the life of the transmission asset, or who will own or control the investment once it is made. Under these circumstances, utilities will avoid any investments other than those absolutely necessary to maintain system reliability.

Utilities are relying more and more on capacity purchases from neighboring sources, but delivering those sources to deficient areas will become more difficult as the system becomes increasingly constrained. An important factor to consider here is that significant changes in return on transmission investments can be provided with only minimal increases in the electric bill. For example, assume the transmission operator doubles its annual expenditures in order to keep up with demand. To attract the needed capital, regulators set a 5-year depreciation schedule and a $20 \%$ after-tax return on new capital, but adhere to rate-of-return regulation.

\footnotetext{
""Market Architecture," Robert Wilson, Stanford University.
} 
The incremental return on capital invested in new facilities would require a price increase of about $15 \%$ that translates into about $1 \%$ for the average electric bill.

Another alternative is the formation of an ITC. An ITC is independent from generation ownership and control, but is a profit making entity that owns assets. It can also plan, finance and execute its expansion, but it must follow reliability rules and suffers commercial penalties for inadequate reliability or service. Finally, it should benefit (create value for its shareholders) from efficient operation and growth of its market. One concept is a three part transmission tariff that includes an access charge (which compensates the ITC for investment in fixed assets), a volume charge (which encourages the ITC to find ways to accommodate more traffic), plus a congestion charge to deter placement of generation at inconvenient locations (the funds which the ITC would have to pay back to consumers). The tariff should force the ITC to choose wisely between a decision to invest versus the decision to carry more over the existing system.

After transmission expansion plans have been completed, there is still a long lead-time before the lines are placed in service. In the past, after the relative merits of transmission grid modification plans had been evaluated by the utility and regional reliability councils, the utility would begin a process of regulatory approval, certification, financing and construction that could take as long as 5 to 10 years.

\section{RESPONSIBILITIES OF AN ISO VS AN RTO}

An ISO's responsibilities are primarily directed toward system operation. The issues of when, where and why to invest in additional transmission facilities are generally not within the purview of the system operator, although most proposals do acknowledge an important advisory and coordination function that the system operator can play in investment planning. The answers to the following important questions delineating the full extent of the ISO's responsibilities and authority are still being established:

- Should the ISO be authorized to do planning, or simply facilitate and coordinate plans of transmission owners in the system?

- Should the ISO be allowed to override the capital budgets of the transmission owners?

- $\quad$ Should the ISO be allowed to construct and own facilities for itself?

*"Designing Competitive Electricity Markets", Paper 9, "Investing in Transmission Facilities - Why, by Whom and for Whom", Martin L. Baughman, 1998, Kluwer Academic Publishers 
- Should the ISO be allowed to arrange alternative financing for new facilities?

- Should the ISO be allowed to arrange for alternative transmission owners?

\section{FERC RULEMAKING}

On May 13, 1999, FERC issued a Notice of Proposed Rulemaking (NOPR) on RTOs to require that each public utility that owns, operates, or controls facilities for the transmission of electric energy in interstate commerce make certain filings with respect to forming and participating in an RTO. FERC went on to state that the traditional means of grid management are showing signs of strain and may be inadequate to support the efficient and reliable operation that is needed for the continued development of electricity markets. In addition, there are indications that continued discrimination in the provision of transmission services by vertically integrated utilities may also be impeding fully competitive electricity markets. The NOPR goes on to state:

Our objective is for all transmission owning entities in the Nation, including non-public utility entities, to place their transmission facilities under the control of appropriate regional transmission institutions in a timely manner.

The Commission is proposing to establish fundamental characteristics and functions for appropriate regional transmission institutions. The characteristics and functions could be satisfied by different organizational forms, such as ISO's, transcos, combinations of the two, or even new organizational forms not yet discussed in the industry. FERC stops short of compelling formation of RTO's. FERC only requires that transmission owners state what their plans are. 


\section{ALTERNATIVE MARKET STRUCTURES}

Competitive markets must deal with generation, transmission and secure operations. To this end all restructuring models separate the system operator from the commercial functions. Either through corporate divestiture or codes-of-conduct, the system operator can not be allowed to use its position or information for profit by manipulating the energy market.

At a minimum a vertically integrated utility must segregate its off-system marketing function from its system control. Alternatively, an ISO can be formed as a separate corporate entity to operate the system reliably and to accommodate commercial transactions. A third choice can have an RTO operate the transmission system (either for profit or as a non-profit entity). A fourth choice can have the independent system operator take on the minimal role of monitoring the system for reliability concerns, allowing other operators to accommodate commercial transactions and acting only when system security is threatened."

Transactions can be accommodated through a power exchange (PX), through bilateral transactions or through both. If a PX exists it can be voluntary or mandatory. With a mandatory PX generators are only allowed to sell to the PX and customers are required to purchase all of their power from the PX. A PX may be operated by the ISO or by a third party. It is possible to have multiple PXs operating in the same geographic region.

\section{GENERATION}

Generation can be readily moved into a competitive market environment. Usual concerns over market power exist, sometimes made worse by transmission congestion limiting the geographic scope of the local market. The entire commercial investment and operating risk can be placed on the generator owner. At least two mechanisms can be used to maintain generation adequacy:

Rely on markets, the interactions of consumers and suppliers acting through the mechanism of volatile spot prices, to decide what types of generation to build and how much electricity to consume when. California adopted this approach.

"The Texas ISO and the NERC regional security coordinators work essentially this way. 
Rely on the traditional system of having a central agency (e.g., the ISO or state regulator) specify an appropriate minimum reserve margin based on estimates of the value of lost load (VOLL) to protect customers from their own inaction, and other factors (e.g., forced and planned outage rates for different types of generating units). This reserve margin is then imposed on all load-serving entities (LSEs). The three Northeastern ISOs (PJM, New York, and New England), all of which developed from traditional tight power pools, use this approach.

The United Kingdom uses a third system. There, the NGC calculates, on a day-ahead basis, the expected loss-of-load probability (LOLP) for each 30-minute period. This LOLP is then multiplied by the assumed VOLL of about $\$ 4 / \mathrm{kWh}$ to develop a capacity charge, which is added to the system marginal price (SMP). This approach has received little attention in the United States, perhaps because the capacity charge is too easy to manipulate for companies that own large amounts of generation. They can do so primarily by declaring units unavailable in the day-ahead market and then redeclaring them available in real time to collect the high capacity charge caused by the unavailability declarations.

\section{TRANSMISSION}

Transmission presents a greater challenge in restructuring. Open access does not equate to a change in responsibility for the T\&D system reliability, which still falls on the shoulders of the state regulatory bodies and now, potentially, on the ISOs/RTOs. Competitive markets for generation and retail services can be accommodated with monopoly management of transmission operations and investment. The monopoly could take on the obligation to provide unlimited transmission service for everyone. The monopoly would make investments and/or pay for redispatch to manage congestion. The NGC in England and Wales works essentially this way. All the usual problems with regulating and providing appropriate incentives to a powerful monopoly still exist.

There is an alternative to complete monopoly management of transmission expansion. In spite of the difficulties and complexities, several schemes have been proposed for pricing transmission based on locational electricity prices. ${ }^{*}$ The current inability to economically

\footnotetext{
*W. W. Hogan 1998, Transmission Investment and Competitive Electricity Markets, John F. Kennedy School of Government, Harvard University, Cambridge MA, April.

S. S. Oren 1997, "Passive Transmission Rights Will Not Do the Job," The Electricity Journal, 10(5), 22!33, June.

R. D. Tabors and L. P. Galindo 1999, Transmission Pricing in PJM: Allowing the Economics of the Market to Work, Tabors Carmanis \& Associates, Cambridge, MA, February 24, 1999.
} 
control individual line flows in AC power networks makes completely independent transmission projects and markets impractical. The ability to create congestion and drive locational prices apart through inappropriate operation of the transmission system creates a need to separate physical control of the transmission system from the rights to profit from congestion. Thus, the network needs a system operator, independent of market outcomes, to manage real-time operations. Flows will distribute themselves among the transmission lines based on the locations and magnitudes of generation and load as well as the impedances of the individual transmission elements. Therefore, it would not be feasible for a transmission owner to place a "toll booth" on a particular line and levy a charge for every transaction that used that line. But something that is economically similar can be developed.

Hogan describes TCCs that are equivalent to perfectly tradable physical transmission rights: ${ }^{*}$ "With such contracts to allocate transmission benefits, it would be possible to rely more on market forces, partly if not completely, to drive transmission expansion." In Hogan's scheme, transmission service is priced partially on the nodal price differences. Nodal price differences result when transmission is congested and there is insufficient transmission capacity to move lower-cost power to higher-cost locations.

Congestion is not exclusively related to the actual flows on lines. Congestion occurs when security-constrained dispatch requires modification of the economic dispatch. This situation occurs most frequently as the result of contingency analysis rather than because of steady-state line flows. The generation dispatch is modified because a line will overload if a specific contingency occurs (e.g., a generator or transmission line trips). Because there is no time to take corrective action after the event has occurred to prevent cascading failures, it is necessary to preemptively modify the generation dispatch. It is this off-economic dispatch that results in locational price differences. (Losses also cause locational price differences but have a much smaller impact and are easier to deal with than congestion.)

Why is congestion so much more important a problem now than it was a few years ago? The traditional vertically integrated utilities accounted for transmission constraints when they made their daily operating (unit-commitment) plans. Thus, they used their generating resources in way that would not overload the network. In today's increasingly competitive environment, suppliers schedule resources without a detailed knowledge of transmission constraints.

Advances in power electronics such as Flexible AC Transmission System (FACTS) devices now allow dynamic control of voltage, line flow, capacitive and reactive power, etc. In the

*Oren proposes active rights and link-based contracts instead of TCCs. Tabors argues that most of the effects of congestion can be accounted for on a zonal, rather than nodal, basis. In either case, the detailed distinctions may be important to implementation but do not affect the conclusions of this discussion. The Hogan, Oren, and Tabors schemes all encompass the same basic requirements. 
future, the ability to control line flows will make completely independent transmission projects and markets possible. Any technology advance that significantly reduces the cost of high voltage/power semiconductors could dramatically change the way transmission regulation and investment is viewed. If FACTS devices, DC lines and DC links become cheap enough to allow flow control over most congested interfaces, private capital could be attracted to transmission investment. The electric power grid could behave much more like the gas pipeline network. Many of the same regulatory strategies that encourage private investment in gas pipelines could then be used to provide investment incentives for electric power transmission lines.

\section{TCCs AND TRANSMISSION INVESTMENT}

TCCs can help allocate scarce transmission among competitive users in the short term but they only partially help with transmission investment in the long term. For example, congestion contracts covering the additional capacity created by transmission enhancements can be awarded to the investor. The system operator uses the same system models that allocated the original TCCs to determine what additional TCC capacity is created by the transmission enhancement. All existing TCC rights are preserved, and the investor gets the new TCC rights.

An interesting problem arises however. Note that the investor gets the new MW capacity but congestion prices are likely reduced, possibly to zero. So, although everyone's rights are preserved, the value of those rights can be wiped out. Hence, congestion contracts will most likely be tied to the generators or loads that profit from reduced congestion rather than to investors speculating in congestion or building transmission for profit. Although generators or loads lose the value of their congestion contracts, they gain as much or more from reduced power prices at the receiving bus or increased prices at the sending bus.

This impact of significant transmission enhancement on locational prices creates a free-rider problem that may make it difficult to get investors to invest. Each party is better off if someone else makes the investment. The problem is compounded by the scope and scale problem. It would be desirable to invest only enough to cover the exact amount of transmission capacity required by the individual needs. Then any new requirement will cause congestion and there will be a price differential that the investor's TCC will collect rent from. But that is hard to do. It is generally much cheaper to oversize a line when constructing it than it is to come back later and upgrade it. Similarly, in an interconnected system, economies of scope often mean that an enhancement removes constraints on a number of transmission paths. Customers using one path may choose to wait until the customers using another path make the investment. The longevity of transmission equipment (roughly 50 years or more) adds a further complication.

One may build a transmission line between two locations that enhances system reliability and improves the overall social welfare, yet, because of counterflow, the nodal price difference 
across that line may be negative so the TCC associated with the new line has a negative value." The "thin line effect" occurs when a new line connecting two symmetric monopolistic markets creates a duopoly in each market thus reducing prices and increasing social welfare. Due to the symmetry, however, each generator continues to supply the local market so there is no flow on the line. The question is who should pay for the line and how to compensate the investment.

Even if all of the current beneficiaries could agree on the need for a transmission enhancement, they are unlikely to follow through. A user of the transmission facility would have to be able to commit for decades of benefits to pay for the investment. Since the enhancement immediately becomes a sunk cost, providing the benefits at nearly zero incremental cost, there is no ability for the current user to sell its share in the investment if it no longer needs it unless the system becomes congested again.

In cases where it is not practical for specific users to invest to relieve congestion, it may be appropriate to rely on congestion pricing to identify economically sound investment. Once identified and approved by regulators, the transmission enhancement could be built, either by the existing transmission owner or by a third party. The enhancement could then be added to the rate base for all users of the system or for users of a portion of the system.

Eminent domain could also become a problem, making transmission right-of-way harder to obtain for commercial reasons than for reliability reasons. A regulatory approval process could address this problem as well.

\section{TRANSMISSION-PRICING PRINCIPLES}

While congestion contracts may seem complex, several fundamental principles concerning pricing transmission in a restructured industry are generally accepted:

- $\quad$ No one can be allowed to withhold transmission rights; unused capacity is available for others to use.

- The system operator must be involved in the analysis of rights and the calculation of payments for transmission congestion and losses.

- The system operator must not be allowed to profit from congestion.

- Transmission prices should reflect differences in locational power prices.

*Oren et. al. Electricity Journal Paper 1995. 
- Transmission prices can send appropriate signals for the locations of new transmission and generation facilities as well as loads.

- Transmission prices can illuminate the need for transmission enhancement but they are unlikely to provide sufficient incentive to motivate investment without additional compensation.

- The remaining transmission costs will have to be allocated among users.

These principles, unfortunately, do not lead to a completely market-based expansion policy, as is possible with gas and most other industries. This situation leaves most enhancement decisions in the discouraging position of having many interested parties and no uniquely correct solution. To make matters worse, the optimization is often quite flat from an overall system perspective but can have dramatic impacts on individuals. That is, there are often multiple solutions that are, from the system's point of view, equally good (i.e., low in cost). But the differences can be critically important to individual market participants. With a vertically integrated utility, differences in the least-cost solutions did not matter. The customers only paid the aggregated cost. Now it is very important because individuals prosper or starve based on the details of the final decision. The selection procedure can be, or appear to be, arbitrary. For example, a generator located within a congested portion of the grid might be driven out of business if the congestion is relieved, a dramatic result for the owner of that unit. The amortized capital cost of relieving the congestion, on the other hand, may be only slightly lower than the off-economic dispatch cost, a small impact on the overall system. The fact that the decision to invest will, of necessity, be based on forecasts makes the problem worse. The transmission solution may actually be more expensive. Finally, the analysis and decision will likely be made by individuals (the ISO and the regulator) that bear no market risk themselves.

With transmission remaining largely regulated and with transmission-enhancement projects often eliminating locational price differences caused by congestion, the problem of allocating the cost of transmission enhancements to customers remains. Some argue that if the cost of the existing transmission system, which connects existing generators to loads, is paid for by retail customers, then it would be anticompetitive to require new generators to bear the cost of the transmission that brings their product to market, although it would be reasonable to require a new generator to pay for any special interconnection and transmission-enhancement requirements. Not surprisingly, potential owners of new generation argue that any additional cost could be included in the transmission rate base if the PUC agrees that the project offers

"Texas Public Utility Commission 1998, Report to the Texas Senate Interim Committee on Electric Utility Restructuring, Austin, TX, July. 
unusual benefits to the system. Texas Utilities proposes a modified scheme in which new generators pay the total cost for facilities that accommodate them and do not increase transfer capability from one region to another. New generators would pay only a pro rata share of the cost of facilities that increase interregional transfer capacity.

\section{ANCILLARY SERVICES}

All of the functions required to reliably operate the power system under the vertically integrated paradigm are still required under a market-based structure. A single commercial entity is no longer both responsible for system reliability and the owner of all of the resources that are used to perform the functions necessary to assure that reliability however. Consequently it is necessary to obtain the required functions through commercial transactions. Table 1 provides a list of the 12 commonly accepted ancillary services along with the time scale over which they operate. The list intends to be both comprehensive and mutually exclusive.

While defining reliability services is a necessary first step, metrics are also required if services are to be bought and sold. Progress is being made in developing metrics (primarily by NERC and its Interconnected Operations Services Committee) but it is slow.

With definitions and standards for services it is possible to create markets for their provision. Since the services are primarily provided by controllable generation that could be used to sell power there are strong interactions between each of the ancillary service markets and the energy market. In fact, the primary cost in supplying many of the ancillary services is the lost opportunity cost incurred by foregoing participation in the energy market."

The reliability functions must be under the control or supervision of the system operator. At least two approaches are possible for the system operator to commercially obtain the required reliability functions. The system operator can either contract for the control of the resources that are to provide the services or the operator can contract for service provision. If the system operator contracts for service provision, rather than for control of the resources, the markets for each ancillary service and for energy must be coordinated. This can be done by operating the markets in a fixed sequence or by running the markets simultaneously. Simultaneous operation of the markets requires that the market clearing function somehow resolve multiple objectives. Should the market clearing function try to minimize total customer cost? Clearly it should not try to maximize generator profit. But if it does not maximize generator profit within the constraints of the services the generator can sell the generator may find it has an

\footnotetext{
" "Unbundling Generation and Transmission Services for Competitive Electricity Markets, " Eric Hirst and Brandan Kirby, ORNL/CON-454, January 1998.
} 
incentive to artificially constrain its capabilities if this will force it into a more favorable ancillary service market. 


\section{Table 1. Ancillary Services and their Definitions}

\begin{tabular}{|c|c|c|}
\hline Service & Description & Time scale \\
\hline \multicolumn{3}{|c|}{$\begin{array}{l}\text { Services FERC requires transmission providers to offer and customers to take from } \\
\text { the transmission provider }\end{array}$} \\
\hline System control & $\begin{array}{l}\text { The control-area operator functions that schedule generation and } \\
\text { transactions before the fact and that control some generation in real-time } \\
\text { to maintain generation/load balance; Interconnected Operations Services } \\
\text { Working Group definition more restricted, with a focus on reliability, } \\
\text { not commercial, activities, including generation/load balance, } \\
\text { transmission security, and emergency preparedness }\end{array}$ & $\begin{array}{l}\text { Seconds to } \\
\text { hours }\end{array}$ \\
\hline $\begin{array}{l}\text { Reactive supply } \\
\text { and voltage } \\
\text { control from } \\
\text { generation }\end{array}$ & $\begin{array}{l}\text { The injection or absorption of reactive power from generators to } \\
\text { maintain transmission-system voltages within required ranges }\end{array}$ & Seconds \\
\hline \multicolumn{3}{|c|}{$\begin{array}{l}\text { Services FERC requires transmission providers to offer but which customers can take from } \\
\text { the transmission provider, third parties, or self-provide }\end{array}$} \\
\hline Regulation & $\begin{array}{l}\text { The use of generation equipped with governors and automatic- } \\
\text { generation control to maintain minute-to-minute generation/load } \\
\text { balance within the control area to meet NERC control-performance } \\
\text { standards }\end{array}$ & $\sim 1$ minute \\
\hline $\begin{array}{l}\text { Operating reserve } \\
\text { - spinning }\end{array}$ & $\begin{array}{l}\text { The provision of generating capacity (usually with governors and } \\
\text { automatic-generation control) that is synchronized to the grid and is } \\
\text { unloaded that can respond immediately to correct for generation/load } \\
\text { imbalances caused by generation and transmission outages and that is } \\
\text { fully available within } 10 \text { minutes }\end{array}$ & $\begin{array}{l}\text { Seconds to } \\
<10 \text { minutes }\end{array}$ \\
\hline $\begin{array}{l}\text { Operating reserve } \\
\text { - supplemental }\end{array}$ & $\begin{array}{l}\text { The provision of generating capacity and curtailable load used to correct } \\
\text { for generation/load imbalances caused by generation and transmission } \\
\text { outages and that is fully available within } 10 \text { minutes }{ }^{\text {a }}\end{array}$ & $<10$ minutes \\
\hline \multirow[t]{2}{*}{ Energy imbalance } & $\begin{array}{l}\text { The use of generation to correct for hourly mismatches between actual } \\
\text { and scheduled transactions between suppliers and their customers }\end{array}$ & Hourly \\
\hline & Services FERC does not require transmission providers to offer & \\
\hline Load following & $\begin{array}{l}\text { The use of generation to meet the hour-to-hour and daily variations in } \\
\text { system load }\end{array}$ & Hours \\
\hline Backup supply & $\begin{array}{l}\text { Generating capacity that can be made fully available within one hour; } \\
\text { used to back up operating reserves and for commercial purposes }\end{array}$ & $\begin{array}{l}30 \text { to } 60 \\
\text { minutes }\end{array}$ \\
\hline $\begin{array}{l}\text { Real-power-loss } \\
\text { replacement }\end{array}$ & $\begin{array}{l}\text { The use of generation to compensate for the transmission-system losses } \\
\text { from generators to loads }\end{array}$ & Hourly \\
\hline $\begin{array}{l}\text { Dynamic } \\
\text { scheduling }\end{array}$ & $\begin{array}{l}\text { Real-time metering, telemetering, and computer software and hardware } \\
\text { to electronically transfer some or all of a generator's output or a } \\
\text { customer's load from one control area to another }\end{array}$ & Seconds \\
\hline $\begin{array}{l}\text { System-black-start } \\
\text { capability }\end{array}$ & $\begin{array}{l}\text { The ability of a generating unit to go from a shutdown condition to an } \\
\text { operating condition without assistance from the electrical grid and to } \\
\text { then energize the grid to help other units start after a blackout occurs }\end{array}$ & $\begin{array}{l}\text { When outages } \\
\text { occur }\end{array}$ \\
\hline $\begin{array}{l}\text { Network-stability } \\
\text { services }\end{array}$ & $\begin{array}{l}\text { Maintenance and use of special equipment (e.g., power-system } \\
\text { stabilizers and dynamic-braking resistors) to maintain a secure } \\
\text { transmission system }\end{array}$ & Cycles \\
\hline
\end{tabular}

${ }^{\mathrm{a}}$ Unlike spinning reserve, supplemental reserve is not required to begin responding immediately. 


\section{ACTUAL IMPLEMENTATIONS}

Restructuring is taking different forms in different locations around the country and around the world. There is no clear consensus yet on what is the "best" approach. Examining several implementations provides insight into what works and what does not.

\section{CALIFORNIA IMPLEMENTATION OF BULK POWER MARKET}

\section{Energy Market}

The California model has been developed so that the ISO itself plays a relatively minor role in scheduling and pricing generators prior to actual dispatch. The California market requires generators to be scheduled for operation on a day-ahead basis, and allows for adjustments in these day-ahead schedules in the "day-of" market up to four hours ahead of actual dispatch. However, almost all scheduling is carried out by a number of Scheduling Coordinators (SCs) that are required to submit balanced generation with load schedules. The ISO's primary point of contact is the SC; the ISO contacts the generating station directly only in an emergency situation. The SCs participate in the forward energy markets; the ISO manages the spot market and also conducts the transmission and ancillary services markets.

The PX was established as California's "official" energy market. The PX runs auctions that establish energy prices on both a day-ahead and day-of basis. It currently handles most of the trading in the California market. All California utilities are required to bid their generation and loads into the PX for the first four years of the California market. PX prices are posted; this makes the market more transparent. After the PX conducts its day-ahead market for energy, the ISO conducts a market for transmission and ancillary services. Finally, the ISO conducts the spot market in "real time". The PX does not address transmission constraints; the ISO resolves transmission congestion after the PX's energy market closes.

The ISO has a Market Surveillance unit that monitors the markets and develops indicators of how the markets are performing. Some of the indicators are: market price for services, sufficiency and quantity of participant bids, the amount of congestion on transmission paths

\footnotetext{
""The Role of the ISO in US Electricity Markets: A Review of Restructuring in California" L. Cameron and P. Cramton, The Electricity Journal, April, 1999.
} 
and the congestion changes, and measures of the competitiveness of the market. Market Surveillance seeks to identify deliberate or inadvertent violations of the ISO's market rules and protocols that can affect the efficiency of the market. It continually reviews these rules and protocols, evaluates their impacts on the market and recommends changes to improve market performance and efficiency.

The basic features of the California design are:

- $\quad$ The PX is separated from the ISO, thus in a sense allows competing PX's in the form of SC's.

- $\quad$ The units self commit for the most part.

- $\quad$ There is minimum interference by the ISO in market operation; congestion relief is handled by incremental/decremental bids; the ISO cannot redispatch for economic reasons beyond what is needed for congestion relief.

\section{Zonal Congestion}

Congestion that occurs at zonal boundaries is referred to as interzonal congestion, while congestion within zones, which is expected to be less frequent, is referred to as intrazonal congestion. The ISO manages intrazonal congestion in real time by utilizing energy adjustment bids. Resources located in the same zone as the constraint are incremented and decremented by the use of Energy Adjustment bids, then Supplemental Energy bids. If there are inadequate bids to solve congestion, the reliability must run (RMR) resources are utilized. It may be necessary to skip steps to mitigate emergencies. If this happens, the ISO is expected to resolve the emergency first, then replace the necessary emergency actions with the steps outlined in the correct order. The objective is to always try to use the market first and the RMR generation second.

If the SC's combined schedules do not produce interzonal congestion, the ISO accepts the SC's preferred schedules and interzonal transportation costs are zero. On the other hand, if these combined schedules give rise to congestion, the ISO will price the right to move power across a congested path using schedule adjustment bids submitted by the SC's. The schedule adjustment bids are based on the SC's cost of generation in the various zones. SC's are permitted to change their preferred schedules and to trade with one another. The ISO bills the final interzonal transmission charge to all SC's that have scheduled interzonal flows in the day-ahead market.

*Market Surveillance Frequently Asked Questions, http:oasis.caiso.com 
If energy adjustment bids and supplemental energy bids are exhausted, RMR resources may be used to solve congestion. If there are insufficient bids located in the same zone where the constraint resides, step two allows for the use of bids outside the zone of constraint. This is only allowed under emergency conditions, or if step one is fully exhausted. If step two is depleted, step three allows for Pacific DC Inter-tie mitigation measures. This may involve actually moving schedules to the Pacific DC Inter-tie. If conditions persist and step three cannot solve the congestion, step four allows for any resources in the zone of congestion to move via "out of market" requests as required. If conditions still persist, step five allows the ISO the ability to re-dispatch all resources as necessary including requesting help from other control areas.

\section{Ancillary Service Market}

The ISO also conducts a day-ahead market for four ancillary services: regulation, spinning reserves, non-spinning reserves, and replacement reserves. Suppliers submit bids for these four markets with their day-ahead energy schedules. The ISO resolves the four ancillary service markets in sequence, procuring regulation first and replacement reserves last. Bids that are not accepted in the first market may be transformed to become a bid in the second market. The ISO will procure adequate services within the Control Area to maintain scheduled frequency and avoid loss of firm load following transmission or generation contingencies in accordance with Section 2.5 of the ISO tariff, and the criteria of WSCC and NERC.

In general, the ancillary services are procured from providers operating within the ISO controlled grid. Resources outside the control area are trying to gain access of the California markets.

The ISO determines the amount and location of Black Start capability it requires. The ISO accounts for the probability that some Black Start Generating Units may fail to start or that transmission system damage may prevent some Black Start Generating Units from serving their intended loads. The ISO selects black start capacity in locations where adequate transmission capacity can be made readily available (assuming no transmission damage) to connect the Black Start Generating Unit to the station service bus of the generating units designated by the ISO as next start units.

RMR units are committed and dispatched by the ISO to meet any local area operating constraints (such as to relieve thermal transmission limitation) as well as any shortfalls in the Ancillary Services Market. The RMR generation dispatcher (within the ISO) is responsible for monitoring and making real time changes to generating units that are providing RMR services. The RMR generation dispatcher works closely with the transmission dispatchers and the generation dispatchers (also, within the CAISO) to ensure that market energy and A/S schedules being provided by the RMR units are maintained so that system reliability is not compromised. The RMR dispatcher takes into account any equipment outages or deratings 
of transmission lines or generating units when determining which RMR units must be committed under RMR contracts. For areas that contain several RMR units that are capable of satisfying the requirements, the RMR dispatcher has available an economic analysis tool to determine which units to dispatch based on energy costs."

The process for determining if additional $\mathrm{A} / \mathrm{S}$ will be required from RMR units is a manually intensive process that may require the dispatcher to make modifications to many unit's schedules. During an independent control room study, observers noted that over 20 hours of observations, the RMR generation dispatcher required two hours to complete the task of determining whether or not additional A/S from RMR units were required.

\section{Grid Planning Process}

The ISO Grid Coordinated Planning Process is flexible in that projects can be generated from a variety of sources including the transmission owners, the ISO, or any entity who participates in the energy marketplace. In addition to protecting reliability, the planning process seeks to enhance operating flexibility, reduce congestion and minimize the need for must run contracts.

The Participating Transmission Owners (PTO's) file annual transmission plans. These plans are to be coordinated with neighboring systems and are to describe the proposed facility additions over a minimum five-year planning horizon. The various power flow and stability cases developed for these annual plans will be available to the ISO and other market participants so that integrated review and independent studies can be accommodated.

Once projects are identified, they go through the same Western Interconnection Coordinated Transmission Planning Process that is in place today. All ISO Grid projects go through an ISO review process to ensure that projects connected to the ISO grid meet the ISO grid planning criteria. In addition, the ISO will conduct an operational review to ensure that the projects meet the ISO's needs for operational flexibility.

Having all these interests participate in the planning process is expected to facilitate the development of projects that will result in an ISO Grid that best meets the needs of all its users and maximizes the potential benefits to the State of California. The goal is to meet the reliability needs of the state at the minimum cost to the consumer. The various projects that will be developed through this process will fill a number of needs including the following:

- Interconnecting generation or load

- $\quad$ Protecting or enhancing system reliability

- Improving system efficiency

*Study of CAISO Control Room Operations, Phase II Report, DRAFT, April 9, 1999. 
- $\quad$ Enhancing operating flexibility

- $\quad$ Reducing or eliminating congestion

- $\quad$ Minimizing the need for must-run contracts

California has some grid areas that periodically experience congestion. These are the interface between Northern and Southern California, The San Francisco peninsula, and San Diego County. The mandate and role of the California Energy Commission, traditionally the resource planning agency, is being redefined as a result of restructuring. They no longer clearly hold the responsibility for planning changes to the transmission grid. The who, what, and when of transmission expansion does not appear to be totally spelled out. Specifically, there are six main unresolved issues, as follows:

a. How to identify proposed projects in an overall optimal fashion, rather than just based on PTO preferences.

b. How to compare capacity addition with other mitigation measures, e.g. capacitors.

c. How to coordinate selection of projects for FERC cost recovery in tariffs.

d. How to make the overall incentive structure one that will result in adequate/optimal PTO investment.

e. How to accommodate ownership of excess capacity if line interconnect capacity for a new project is lumpy and exceeds needed project capacity and how to capture economies of scale in interconnect capacity.

f. How to create a transparent system - important because interests are strongly affected by choices of transmission projects.

\section{Market Concerns}

The Market Surveillance function described above evaluates whether or not a participant is exercising market power. Market power is the ability to significantly influence market prices and cause them to vary from competitive levels for an extended time. Participants who have market power may control a large share of the market or can exercise control under certain market conditions. As an example, when significant barriers to market entry exist, the ISO receives insufficient bids for ancillary services in some hours. Under those conditions, any price bid would be accepted and set the market-clearing price. This market power may be temporary if additional bidders make the market competitive at a different time. Price caps are one method the ISO uses to mitigate temporary market power. A market participant can exercise market power by physically or economically withholding generation. It can schedule generation units to cause congestion over specific transmission paths or between specific geographical areas. It can also price and bid its resources in a way that impedes the efficiency of the market and unfairly benefits the participant exercising market power. These behaviors can become market power abuse, however, at times they can be acceptable competitive behavior highlighting the need for clear and effective market rules. 
Prices above marginal cost are not necessarily an indication of market power. The distinction must be made between market power and legitimate scarcity rents that are needed to compensate capacity and assure adequacy. There must also be a distinction between exercise of market power through withholding of supply vs. exploiting arbitrage opportunities among the energy and ancillary service markets or forward and real time markets. There is sometimes difficulty in drawing such a distinction. For instance, the PX surveillance committee recently claimed that there were 100 hours during which generators withheld bids to increase prices. Some argue that the generators simply were exploiting arbitrage opportunities saving their bids for the real time market that was yielding a higher price.

The PX and ISO each have a unit tasked with monitoring market rules and operation to ensure that the markets under their control operate fairly and efficiently. The ISO and the PX exchange data, monitoring methodologies and information on corrective actions taken. They perform joint investigation where appropriate.

The ISO has had a deficiency in the number of bids in its spin, non-spin, and replacement reserve ancillary service markets. The markets have been "thin," i.e.; too few bids are received to completely meet the ISO's requirements in all hours. One result is that the ISO has had to call upon RMR units to provide additional regulating capacity. A thin market results in less competition and can mean higher market clearing prices (MCPs) than if more participants were bidding.

During on-peak and off-peak hours, scheduled load submitted by SCs often underestimates the actual load encountered, thereby increasing the amount of energy which must be procured as imbalance energy to meet real time demand. In comparing the aggregate SC's day-ahead generation schedules to the CAISO's actual load forecast, it was found that the approximate generation shortfall during on-peak hours was up to 3,500 megawatts and 1,000 megawatts for off-peak hours. In response to the under scheduling of load, the CAISO began adding a variable to SC load forecasts to more accurately reflect the CAISO's forecast of load.

The ISO had instituted a temporary Regulation Energy Payment Adjustment (REPA) that was designed to encourage more generators to bid regulation service. The ISO governing board suspended the REPA payment until such time that the governing board determines that REPA is needed to alleviate regulation market conditions.

The current protocol for purchasing Ancillary Services involves the independent sequential evaluation of bids for different services, with the market for regulation cleared first, followed by the markets for Spinning Reserves, Non-Spinning Reserves, and Replacement Reserves in that order. Announcing a price-inelastic demand for each service and employing a strict sequential bid evaluation process enhances the ability of market participants to set excessive MCPs. However, a "rational buyer" trying to meet the ISO's ancillary service requirements would substitute a lower-priced, higher quality service for a higher priced, lower quality 
service." A protocol, "The Rational Buyer's Protocol" is now being developed to permit the ISO to do this.

Unlike regulation, spin, non-spin and replacement reserve, the ISO does not have specific requirements for supplemental energy or load following. During the peak hours, the ISO would like enough decremental energy bids to allow a 1,000 MW reduction to help it match load and generation. It has not been receiving that level of bids. It has had to call upon RMR units so they are available to reduce generation when a real-time imbalance occurs. As market participants gain more experience, the number of decremental bids may increase as they realize that even a very low bid has a high probability of being accepted.

During an independent study of control room operations, several instances were noted where SC's, in response to the generation dispatcher's dispatch instruction, declined to dispatch the energy associated with their Ancillary Service and/or supplemental energy bids. Some SC's indicated that resources were not available due to forced outages, but in most cases the SC did not provide a reason. In some cases, SCs who had submitted Supplemental Energy bids over many consecutive hours during the operating day (or over many days) declined to dispatch these resources. Instead of withdrawing these supplemental energy bids (which can be done up until 45 minutes prior to the operating hour), the SC's left these bids in place which results in additional uncertainty for the generation dispatcher. SC's are subsequently charged (as imbalance energy) for the energy that they declined to provide from their A/S and/or supplemental energy bids. Underscheduling of load by the SCs was due, in part, to the method of $\mathrm{A} / \mathrm{S}$ cost allocation which encouraged under scheduling. This will be corrected in the Ancillary Service redesign.

FERC has recently issued an order approving a CAISO proposal that would eliminate payments for capacity committed to the CAISO for supply of Ancillary Services when that same capacity is instead utilized to produce Energy in the form of an uninstructed deviation. The approved proposal would also eliminate payments for the Energy generated from this uninstructed deviation. It is anticipated that the elimination of capacity and Energy payments will encourage all SCs to more rigorously comply with CAISO Dispatch Instructions in the future.

Although FERC approved the elimination of capacity and Energy payments to SCs for Uninstructed Deviations with regard to the A/S bids, the CAISO proposal did not address instances in which SCs decline to provide Energy bids as Supplemental Energy. Depending on how the market responds to the pending non-payment provisions, the CAISO may seek

"The Opinion of the CAISO Market Surveillance Committee on the Rational Buyer Protocol, January 26, 1999. 
additional relief from FERC to strengthen incentives for SCs to update their Energy schedules in the Hour-Ahead Market and to remove Supplemental Energy bids that cannot be provided.

\section{Observations}

The market has been experiencing a number of problems, as it matures, such as too few bids for some services, extensive reliance on RMR units, and apparent market power from some generators. The ISO has instituted several "fixes" to deal with these problems and has obtained FERC orders in some instances, but there are still opportunities that continue to be available for generators to game the system or where rules do not result in the desired behavior.

\section{PJM IMPLEMENTATION OF BULK POWER MARKET}

\section{MCP and Locational Marginal Price (LMP)}

In 1997, the PJM ISO used a MCP, which resulted in a single pool-wide rate. While this system worked well when there was no transmission congestion, it had serious problems when congestion occurred. This system allowed market participants the flexibility to choose between bilateral transactions and spot purchases, but did not simultaneously present them with the costs of their choices. The circumstances created a false and artificial impression that savings of $\$ 10$ per megawatt hour (MWh) or more could be achieved simply by converting a spot transaction into a bilateral schedule across a congested interface. Using this pricing incentive, market participants responded naturally by scheduling more bilateral transactions than the transmission system could accommodate. In effect, using the wrong prices induced behavior that greatly increased the cost of congestion and spread that cost among all loads. In June 1997, the ISO had to intervene by restricting the market and constraining choice to preserve reliability. The PJM ISO was fully aware of the perverse incentives of zonal congestion pricing and the problems they created, but without the authority to change the pricing rules, the ISO had no alternatives but to restrict the market."

FERC approved several amendments to the Operating Agreement and Tariff that largely became effective as of April 1, 1998. The LMP is the marginal cost of supplying the next increment of electric energy at a specific location on the network taking into account both generation marginal cost and the physical aspects of the transmission system. LMP, expressed in dollars per megawatt-hour $(\$ / \mathrm{MWh})$, is a pricing approach that addresses transmission system congestion costs, as well as energy costs. LMPs at buses are calculated based upon the

*Getting the Process Right in PJM: What the Date Teaches Us, William W. Hogan, The Electricity Journal, August/September 1998. 
actual economic dispatch and the prices of energy offered. There are approximately 2,000 buses in the PJM control area for which PJM calculates an LMP."

If no constraints are experienced on the transmission system during an hour, the LMP is equal to the bid price of the highest increment of energy that is requested to operate by PJM during the hour. There is one single market price. When there is transmission congestion in the control area, PJM performs one of the following actions: reconfigure, curtail contracts, or redispatch. The redispatch option causes LMP values to separate. The LMP reflects the cost redispatch for less efficient generation and the cost of delivering energy to the location. The congestion cost for a given transaction is the difference in LMP between its source and sink. Thus a party can still purchase the equivalent of firm service by agreeing to pay for resulting congestion to avoid the curtailment of otherwise firm transactions. Market participants can thus pay congestion charges to avoid TLR curtailments. This is sometimes called "buying through" TLR.

The hourly LMP values are used as a component of the calculations of a variety of charges and credits, including spot market energy/interchange billing, operating reserves, transmission congestion, transmission losses, emergency energy and meter error correction processes.

A new system includes a spot market coordinated by the ISO which accepts both the bilateral schedules and the voluntary bids of the market participants and uses them to find an economic, security constrained dispatch for power flows and the associated locational marginal prices.

The ISO has not unbundled its operations in a fashion that allows separate markets in ancillary services such as reserves and voltage support. Ancillary services are treated as part of real power scheduling, with cost-based compensation. Currently, PJM Load Serving Entities (LSEs) must carry planning reserves equal to $20 \%$ of the PJM coincident peak load expected over the coming year. This approach is a safeguard against concerns that immature market mechanisms might not balance supply and demand appropriately.

Sales through the spot market are at the locational prices. The transmission usage charge for bilateral transactions is the difference in the locational prices between origin and destination. The alternate to this system is the physical bilateral market where users purchase physical transmission entitlements instead of paying a rate based on the actual flow and market conditions. The merits of the alternate system have been debated extensively in the process of defining PJM's market structure.

*"PJM Interconnection, Report on Control Activities Placed in Operation Pertaining to the Grid Accounting Processes", June 30, 1998, Price Waterhouse Coopers LLP. 
In June of 1998, the variation in unconstrained prices on the most expensive day increased by almost an order of magnitude to a high of $\$ 300 / \mathrm{mwhr}$. This shows that market participants must deal with substantial changes in prices, even without transmission congestion. There were also periods in June 1998 where the system experienced transmission constraints, locational prices separated, and the opportunity cost of transmission was quite large. The lowest locational prices were sometimes actually negative, where it would be cheaper to pay participants to take power at some locations or generators to back down and so relieve transmission constraints. The highest locational prices were very large, much larger than the marginal cost of the most expensive plant, reflecting the need to simultaneously increase output from expensive plants and to decrease output from cheap plants just to meet an increment of load at a constrained location.

The experience of higher unconstrained prices and fewer constrained hours in June 1998 shows that the period of peak system load is not necessarily the time of greatest transmission congestion. Transmission congestion reflects an imbalance in the location of load and generation. At peak load, more generation comes on line and may relieve system congestion. However, during a heat storm in July 1999, LMP prices reached their limit of $\$ 999 / \mathrm{mwhr}$. This should encourage development of new generation as discussed below.

In April 1999, bids were allowed to become market based, rather than being only cost based as they were earlier. Thus, it is pre-mature to draw conclusions as to how well the system is working.

PJM has an accompanying system of FTRs for on system users to provide financial hedges between locations. These FTRs entitle the holder to receive compensation (rent) for certain congestion related transmission charges. The FTR is a financial contract that entitles the holder to a stream of revenues based on the reservation level and hourly energy price differences across a specific path. The FTR's are sold in an auction that started in April 1999.

The FTRs, or compensation for congestion related charges, are sometimes referred to as congestion rents. They may be used as a hedge against the congestion charges that may develop if the system becomes congested. The FTR is a financial instrument, if the FTR owner does not deliver the energy, someone else will and the owner will receive the "rent" if the line is used. The FTR also obligates its holder to pay when the locational price difference is negative. 
Gaming to capture congestion rents and discourage optimal packaged trades should not occur because traders cannot "create" congestion by quoting phantom schedules." PJM does not measure an overload until one actually occurs.

FERC noted on March 10, 1999, in their approval of the PJM market based rate structure, that the PJM ancillary service market, while still developing, is both complex and critical to efficient reliable operations. The commission directed the ISO to file a report on the ancillary services market's activities within one year.

On July 7, 1999, Connective had to resort to rolling blackouts in the lower portion of the Delmarva Peninsula. The major generating station serving the area had a forced outage, and the first contingency voltage was marginal. With the unusually heavy load conditions present during a heat storm, the post contingency voltage was low enough to trip under voltage relaying on a $69 \mathrm{kV}$ line, and rotating blackouts had to be placed in effect. At that point in time, PJM did not have separate LMP nodes in the southern part of the peninsula. If they did, it is probable that the attractive LMP prices would encourage generators to place generation in the area soon. As it is, at least one generation company is considering building combustion turbines in the area.

\section{Transmission Planning}

PJM prepares a Regional Transmission Expansion Plan (RTEP) which consolidates the transmission needs of the region into a single plan. The RTEP reflects transmission enhancements and expansions, load and capacity forecasts, and generation additions and retirements for the ensuing ten years.

The RTEP will:

a. $\quad$ Provide a 5-year plan to address needs for which a commitment to expand or enhance the transmission system must be made in the near term in order to meet scheduled in service dates.

b. Provide a 10-year working plan that address needs for transmission enhancement and expansion for which commitments would not be required in the near term. Commitments needed in the first 5 years to complete work scheduled for years 6 through 10 will be included in the 5-year plan.

"Inefficiencies of NERC's Transmission Loading Relief Procedures," Rajesh Rajaraman, The Electricity Journal, October 1988. 
c. Provide an assessment based on maintaining the PJM control area's reliability in an economic manner.

d. Avoid any unnecessary duplication of facilities.

e. Avoid the imposition of unreasonable costs on any Regional Transmission Owner (RTO) or any user of transmission facilities.

f. Take into account the legal and contractual rights and obligations of the RTOs.

g. Provide, if appropriate, alternative means for meeting transmission needs in the PJM Control Area.

h. Provide for coordination with existing transmission systems and with appropriate interregional and local expansion plans.

i. Include a designation of the RTO or Owners or other entity that will own a transmission facility and how all reasonably incurred costs are to be recovered.

j. Identify local system limitations discovered in analyzing the bulk transmission system.

\section{Observations}

The PJM market has matured rapidly in making the transition to a nodal system, but there are still significant problems that are being addressed. Generation growth has not kept up with load growth in all areas, and it will be interesting to see next year if the new generation being constructed now will solve the problems that required rotating blackouts after a single contingency this summer. It is possible that these reliability problems may actually become worse as the "maturation" process continues.

\section{ISO NEW ENGLAND IMPLEMENTATION OF BULK POWER MARKET}

May 1, 1999 was the opening date of the wholesale electric energy, capacity and ancillary services markets for the New England Power Pool (NEPOOL) participating organizations. Therefore, it is probably premature to make observations on the operation of the market. However, there are some interesting actions taking place in the development of the market protocols. This provides evidence that the market structure provides the underlying basis for the investment decisions for building new generation. 
A series of debates and filings has been taking place about the structure of the market specifically with the protocols regarding the new generators who wish to build in the area. NEPOOL has also been ordered by FERC to revise its procedures for permitting new generators to tie into the region's grid. The region is a "hot" market for new generation, with a total capacity of $30,000 \mathrm{MW}$ being proposed, although the existing capacity is only about 25,000 MW.

NEPOOL had originally proposed that a System Impact Study (SIS) be completed for each new generator to determine whether the added generation would require expansion of the grid. The proposed method had been criticized as flawed for overstating how many of the proposed projects would actually be built and for assuming that no existing generation would be retired. Clearly, not all the projects are needed. NEPOOL had also requested that it be allowed to impose an "in-service" charge on power imported into the system in addition to normal transmission charges, and NEPOOL had proposed that at least half the cost of transmission additions should be borne by new generators. These policies have created considerable concern among the new generators.

One of the new generators, Champion Paper, proposed building a 175 megawatt combined cycle natural gas-fired plant at a pulp and paper mill it owns in Bucksport, Maine. Champion Paper filed a petition with FERC stating that "This emerging market lies in clear and present danger of severe damage from an unduly discriminatory and preferential set of transmission access tariff rules and unjust and unreasonable assumptions employed by ISO New England, NEPOOL and NEPOOL member utilities." Champion filed an application to build the plant on March 24, 1998, but due to a series of complications had to refile on April 16, 1998. In the interim, 11,030 megawatts in new projects were also filed by other prospective generators. Consequently, Champion was placed in line behind these other projects to get access to the grid, and Champion's place in line was to largely determine when the power the project produces would be curtailed. After an appeal, FERC ordered NEPOOL to restore Champion to its place in line, but Champion had a number of other concerns regarding the cost for transmission upgrades as determined by the SIS follows:

\# The new generators will have to pay for a portion of the transmission upgrades, a cost which existing generators will not have.

\# $\quad$ The procedures assume all new generation must be fully integrated with load, so that any new generator located anywhere in NEPOOL must be able to serve load anywhere in NEPOOL. (Existing generators are allowed to pay for re-dispatch).

\# The SIS procedures assume the existence of the most extreme operating conditions, and assume that constraints on the system can only be remedied by construction of transmission upgrades. 
\# The SIS queue process results in "unreasonable delays" for new generators, since they are required to await the completion of a SIS for each project ahead of them in the queue before their study may be completed.

\# As a result of the delays in the SIS queue process, new generators must gamble potentially millions of dollars on development prior to receiving a completed SIS. In addition, because each SIS assumes that all projects in the queue ahead will be built, the SIS produces inaccurate results. Not all the generation is needed.

\# The SIS process effectively "grandfathers" the preferential rights of existing generators.

A group of independent power producers is leveling a barrage of criticism at a proposal for managing congestion in the New England ISO, saying the proposal demonstrates that the utilities that own the grid are still establishing the operating rules. FERC agreed on March 11, 1999, FERC rejected NEPOOL's resubmitted governance procedures, finding that they "continue to allow a select group of utilities to control all actions of the Management Committee." FERC ordered that revised governance procedures be submitted within 60 days and directed that these newly revised procedures "eliminate the control the vertically integrated utilities in NEPOOL now possess."

NEPOOL's proposal will allocate Financial Congestion Rights (FCRs) only to transmission customers that are paying for firm transmission service under the NEPOOL Tariff. Limiting the allocation of FCRs to transmission customers would deny generators compensation for the loss of the right to firm delivery. The NEPOOL position is that allocation of FCRs to transmission customers will ensure that those entities paying for the cost of the grid receive value in exchange for their payments. The generators, however, which would incur costs imposed by congestion but are not the parties that cause congestion, would lose their means to recover their lost opportunity costs in the event they are constrained.

It is the position of the new generators that FCRs would be the most practical method for recognizing existing and paid-for rights to use the system. FCRs could be used to determine who gets compensated, and in what amounts, for the redispatch costs incurred when the most efficient use of the transmission system requires that some generation units will be constrained up or down to assure delivery of electricity under existing contractual arrangements. The market theory behind locational marginal pricing is that areas that have generation deficiencies will have higher locational prices, thus encouraging the placement of generation in the area. If new generation is denied the benefits of a locational pricing system, the new generation is not going to be placed in the locations where it is needed.

\section{Observations}


The fact that new generators have had so much difficulty in gaining access to the grid is a good indicator of firmly entrenched market power. It seems likely that there will be a series of appeals to FERC to correct inequities. This will probably delay the maturing and efficient functioning of the market. The fact that 30,000 MW of new generation is proposed on a region that only has 25,000 MW currently indicates that markets can address generation adequacy and efficiency. The ISO suspended market operation temporarily in July 1999, after a market design deficiency was identified.

\section{UNITED KINGDOM IMPLEMENTATION OF BULK POWER MARKET}

\section{The Electricity Pool}

The wholesale market mechanism through which electricity is traded at present is called the Electricity Pool of England and Wales. Because of opportunities for gaming, pool operation will undergo major changes in the year 2,000 with a new market system. A discussion of the pool's operation and problems is provided, as follows.

The wholesale power market is presently based on mandatory bidding into a centrally dispatched pool. The Electricity Pool operates a day ahead market. There is an obligation that if an availability declaration is made it should be reasonably achievable. Generators sell electricity into a pool and suppliers purchase out of this pool. The Pool facilitates a competitive bidding process between generators that sets the price paid for electricity each half hour of the day and establishes which generators will run to meet forecast demand. By 10 am each day generators submit "day ahead" bids into the Pool for how much electricity they are willing to generate for every half-hour period of the following day and at what price. These contain for each generating unit the level of output on offer and a number of price parameters, plus any operating constraints, for example the minimum generating levels and rate at which a generating unit can increase or decrease output.

The National Grid Company (NGC) as Grid Operator is responsible for the scheduling and dispatch of generation on the day to meet actual demand. NGC produces a forecast of demand (plus reserve) taking into account weather and demand usage patterns for each half hour of the following day and then schedules the generators' bids to meet this demand. A computer system, Generator Ordering and Loading (GOAL), aims to produce the lowest cost generation schedule for the day as a whole, taking into account all plant limitations and generator bids. This is called the Unconstrained Schedule.

Constraints on the transmission system; availability re-declarations by generators and differences between actual and forecast demand mean that the actual dispatch of plant may not match that anticipated at the day-ahead stage. Generally, the price of the most expensive generating unit required to meet forecast demand in each half-hour sets the price for energy 
known as the SMP. To this is added a Capacity Payment which provides an incentive to generators to maintain an adequate margin over the level of demand. This can be high when the margin narrows, but zero if there is a large excess of generation available.

Generators sell power into the pool at Pool Purchase Price (PPP) (SMP plus Capacity Payment) while suppliers buy from the Pool at the Pool Selling Price (PPP plus Uplift discussed below). Suppliers pay for the amount of electricity they draw off at each Grid Supply Point (where electricity enters the distribution system from the National Grid) increased by a factor designed to take account of average losses on the transmission network.

In England and Wales, Uplift represents the difference between operating an idealized electricity system and operating a practical one. All ancillary service costs form part of Uplift, together with other costs that arise from real system operation.

Since 1994, the NGC has been provided with incentives to manage a significant proportion of Uplift through the Transmission Services Scheme. These arrangements enable NGC to make use of its operations in keeping down overall costs. For instance, by increasing the flexibility of the transmission network by new investment there is a likelihood that the cost of security and maintaining quality of supply can be reduced in real time. Similarly NGC can purchase services in real time if the cost of doing so allows it to run a secure system and further reduce the cost of investments in new plant. As part of the scheme, NGC agreed on targets for transmission services costs such that it receives a proportion of savings achieved below target and is exposed to a proportion of costs above that level. These targets are set by the Office of Electricity Regulation, (OFFER). Uplift costs have fallen significantly since 1994, saving consumers more than $£ 300$ million in total.

\section{Ancillary Services}

Ancillary services are provided by large electricity generators, large electricity users, smaller generators and interconnectors. The main ancillary services are: reactive power, frequency control, black start, reserve and constraints. The NGC has been contracting for ancillary services since 1990. Initially these arrangements were entered into with just 6 providers, in 1998 more than 40 companies provide these services. Services are now provided by both large and small generators, interconnectors and very large electricity users. The smallest user that NGC directly contracts with has a demand of $3 \mathrm{MW}$. Some companies choose to contract indirectly with NGC through an agent. NGC provides an invitation on its web site for anyone that feels they may be able to offer a service to contact them.

Typically $£ 120$ million is spent annually on ancillary service contracts.

\section{Pool Prices}


There has been considerable concern over the winter months about spiky pool prices and the bid structures used by some generators. However, since changes to the GOAL scheduling system were made in March, anomalous high prices have been reduced."

In January, the Director General of Electricity Supply (DGES) warned that he was considering actions he could take to prevent gaming of the electricity trading arrangements. This was followed by a consultation paper four weeks later seeking views on bid simplification and the use of inflexibility markers.

The Pool had, however, already identified an unexpected number of anomalous prices following the introduction of a new version of GOAL in December. Modifications to this system (to eliminate anomalous SMPs being set by the second or third price incrementals in generators' bids) were approved at the February Executive Committee meeting and were implemented on a fast track approach on 18 March 1999.

The design of the system changes to modify the SMP algorithm is currently progressing. Two options are currently being analyzed to identify which can be implemented most quickly and easily. The CEO has continued to monitor anomalous prices, and is now establishing a Market Monitoring Group to formalize this process.

\section{Major Changes Are Being Planned}

OFFER has published a Decision Document in response to their February consultation paper. They welcomed the Pool's modifications, but believe that, if they fail to address manipulation, simplified bidding is appropriate. It appears that there are now plans for major changes.

The main criticism of the pool system was the complexity of the bidding process. The bidding rules were deliberately designed to simulate the actual physical power market. A generator's bid was composed of a start up price, a no-load price, and three incremental prices. Some bidders were quoting zero start up, no-load and first increment, with second incs priced at extremely high levels. In addition, a bidder could set an "inflexibility marker," one of which was to specify a minimum level of output below which the generator must not run. The complex system of inputs and pricing rules made it difficult to determine exactly which unit sets the MCP for each half hour and provided opportunities for gaming." The prices were extremely volatile, and most participants entered into hedging contracts that resulted in fixed prices for the majority of their trading volume. Typically, purchasers pay a premium price when using the hedging contracts.

*"Electricity Pool of England and Wales Newsletter," April 1999.

\#"Where Function Follows Form: International Comparisons of Restructured Electricity Markets," F. Sioshani and C. Morgan, Electricity Journal, April 1999. 
In October 1997, the Minister for Science, Energy, and Industry invited the DGES to consider how a review of electricity trading arrangements might be undertaken. In July 1998, the DGES published a proposal document describing new market based trading arrangements for electricity. In October 1998, the Government accepted these proposals.

The proposals envisage market-based trading arrangements more like those in commodity markets elsewhere. Forwards and futures markets would operate up to several years ahead, evolving in response to demand. A voluntary Short-term Bilateral Market would operate from at least 24 hours to about 4 hours before real time, allowing participants to fine tune their positions. When the Short-term Bilateral Market closes, a voluntary Balancing Market would open with the NGC, in its role as System Operator, accepting bids for incs or decs of generation or demand to enable it to balance the system. There would be a settlement process to reflect differences between contract positions and metered volumes of output and to recover other costs to be borne by market participants.

The Proposals also included a suggestion that a PX be established to allow electricity trading "on-the-day." A conceptual figure of the new trading arrangement is provided below:"

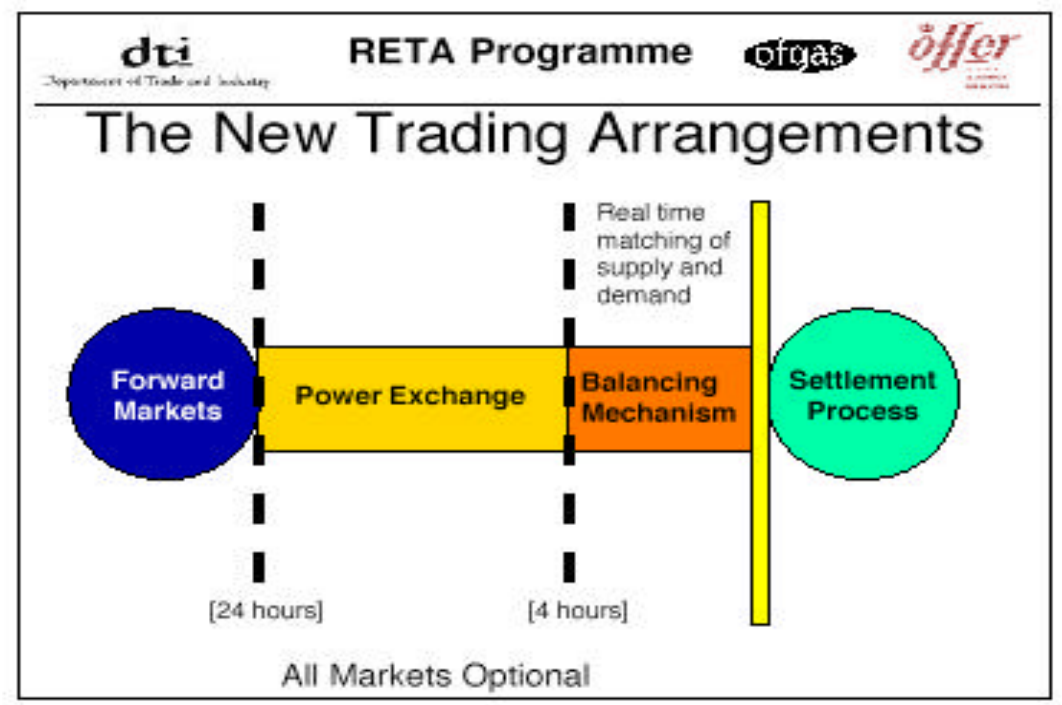

*RETA Seminar, May 19, 1999. 
A Balancing and Settlement Code (the Code) would contain a set of rules covering the balancing market, the imbalance price and the settlement system. It would also govern the relationships of all participants including their responsibilities and duties. This would be supported by a Balancing and Settlement Code Panel with representatives from interested parties to advise on changes to the Code.

The Proposals document set a target date of April 2000 for the introduction of these new arrangements. It recognized the need to establish a major program of change for the industry and all interested parties, and suggested an organizational structure under which the Program would be conducted.

In accepting the DGES's Proposals, the Government indicated that it would legislate to support the changes and specifically endorsed the following suggestions:

OFFER and the Department of Trade and Industry (DTI) should be responsible for the overall direction and leadership of the implementation process. A full-time Program Director should be appointed. The Program should enable the full participation of the industry and its customers. The majority of resources to deal with the technical definition and implementation of the new arrangements should be sought from within the industry and customer groups. Development of the new rules and processes should be overseen by a Development and Implementation Steering Group (DISG) composed of senior staff representing all interested groups within the industry including customers. And the DISG should commission, review, and recommend detailed proposals on the rules, operations, and governance of the new arrangements, via Expert Groups where applicable.

The purpose of the Market Design Group (MDG) is to develop market design proposals, obtain agreement to these proposals from within DTI/OFFER, and then present the output of this process to the DISG. In doing this, the MDG will build upon the work to date of the Expert Groups. Following ratification of these "higher level" proposals, the detailed market design will be undertaken by the Expert Groups/MDG."

\section{Observations}

*Review of Electricity Trading Arrangements, Office of Electricity Regulation, United Kingdom, Website www.open.gov.uk/offer/reta.htm 
It appears that the existing pool system does provide ample opportunity for gaming because of its complexity. The proposed PX appears to have similarities with the California Market. We understand that the target date for the changes to the existing system may be slipping into the Fall of 2000.

\section{IMPLEMENTATION OF ALBERTA BULK POWER MARKET}

The Alberta system is also planning some changes. The existing system of legislated hedges, which was developed to control market power, is being replaced next year with a system called Power Purchase Arrangement, a discussion follows.

The Alberta system is composed of an independent, for-profit, Transmission Administrator (TA) Electric Service Board International [ESBI Alberta Ltd.], and a not for profit power pool system controller, and a market surveillance administrator. The transmission assets are owned by Transmission Facility Owners, and generation is supplied by existing regulated and newly constructed unregulated Generation Facility Owners. All of the energy delivered to the transmission system is bought and sold by Distribution companies, Importers, Exporters, Marketers, and Generators through the Power Pool. There is one zone for the entire control area and the marginal clearing price is the price received by all generators supplying to the pool and paid by all distribution companies, exporters and marketers purchasing from the Pool.

When the system was first developed, a complex system of hedges was put in place to prevent the use of market power by a few large existing generators. The system of legislated hedges was put in place by the government, and the hedges are effectively Contracts for Differences between existing distribution companies and regulated (existing) generators. The legislated hedges rebate to existing distribution companies the difference between the Pool Price and the actual variable cost of production from regulated generation for the bulk of the output of the regulated generators. The pool price can be much higher than the actual cost of production. The fixed costs of the regulated generators are recovered through fixed annual Reservation Payments that are made by existing distribution companies in return for the legislated hedges. Generation levels above the contracted amount can be sold without paying the rebate. This allowed competition to take place without market power from the large generators, but still allowed the large generators to collect a return on their investment.

The Alberta system has limited import/export capability. There is very little price elasticity currently allowed in the load, and reserves are limited. At present, the majority of customers pay fixed rates for electricity and are not exposed to the price spikes which are occasionally 
experienced in the power pool. Because of the price inelasticity of demand, during periods of high load and shortages of supply, spot prices tend to rise very rapidly, almost vertically.

Reserve levels are allowed to drop when all sources of supply have been exhausted and the only other alternative is to shed firm load. When firm load is interrupted the spot price of electricity is automatically set at $\$ 1000$ / MWh. This effectively caps the price of electricity at $\$ 1000 / \mathrm{MWh}$. If the price were not capped it would rise quickly.

ESBI has recently developed a system for contracted interruptible load for users who wish to become Reserve Service Providers. These users receive a warning from the System Controller that the load is being "armed" and is thus being included in the reserve calculation. This load must be capable of being shed within seven minutes (three minutes are allowed for system operator action) and must be greater than or equal to $10 \mathrm{MW}$. Loads may be aggregated provided that requests for service and curtailment requires only one dispatch from the System Controller. So far, few customers have contracted to become Reserve Service Providers, but ESBI is actively seeking to increase the number of participating loads.

Three generation companies control most of the generation in Alberta, but there is significant new generation being planned. In the future, to resolve concerns about Market Power without requiring the divestiture of assets, a Power Purchase Arrangement is being developed where competing marketers buy rights to the generation output of the existing regulated generating stations under long term contracts. With this program, the original plant owner will receive a payment from the marketer covering the fixed and variable cost of production, but the output of the generation will be bid by an independent marketer. The marketers will buy the rights to the generation in an open auction that will be held in 2001. Any amounts received that differ from the book value of the regulated generators will be contributed or deducted from a balancing pool. The net balance of the balancing pool will form either a credit or debit to existing customers. In this way, the residual value of some plants can be used to offset stranded asset costs of other plants.

Because of the occasionally high clearing prices, there are a number of new generators who are planning to build new capacity. It is hoped that Pool Prices will peak in 1999 and decline in 2000 .

The administration of the transmission system is under the purview of the TA. The TA recovers its costs through a tariff for system access. Much of the existing generation is installed in the Edmonton area, while the major load center is in the Calgary area, 180 miles to the south. As a result the North-South transmission corridors become congested during periods of heavy loading. To address this problem, the TA has introduced a transmission 
access tariff based on System Expansion Related Pricing (SERP). Under this scheme, Generators and Distributors will each bear half of the costs of the transmission system. Distributors pay a postage stamp rate regardless of where the Point of Delivery is. This is to encourage economic development in the far North where transmission costs are higher, but economic development is needed.

The transmission access tariff for generators located in areas that reduce the need for system reinforcement is less than the tariff for generators located in areas that put further strains on the transmission system and contribute to the need for system reinforcement. This is to encourage generation to make efficient siting choices. Through the SERP transmission access tariff, the TA is hoping to avoid the need for expensive reinforcement of the North South transmission corridors by encouraging generation to locate in the South of the province closer to the load centers. This system also is subject to revision and refinement next year.

\section{Observations}

Alberta has a system where ancillary services are contracted rather than made part of the market. The Alberta system planning process has been controlled by the government to put a damper on market power and to achieve economic goals. (The government hired the for-profit TA). The planning process has also ensured that potential stranded assets are dealt with and costs are recovered. The problem of planning and paying for needed transmission expansion will be difficult, however, because upgrades to the North - South corridor will not be used if the program to encourage new generation in the south is effective.

\section{IMPLEMENTATION OF THE AUSTRALIAN BULK POWER MARKET}

The restructuring of the electric utility system has been progressing in phases in Australia since 1990. First, a wholesale market for electricity was developed in the Victoria region with a pool administered by the Victoria PX, then other regions followed, and in 1996 a National Electricity Market Management Company (NEMMCO), an ISO, was developed. Generators compete by providing dispatch offers (prices for different levels of generation) to NEMMCO. Customers (retailers and end use customers who are wholesale market participants) submit dispatch bids - prices and quantities they wish to have scheduled for dispatch. NEMMCO dispatches the scheduled generation and demand with the objective of minimizing the cost of meeting electricity demand. ${ }^{*}$

\footnotetext{
*"An Introduction to Australia's National Electricity Market," NEMMCO.
} 
The National Electricity Code defines the terms of participation in the wholesale electricity market (NEM) for generators, transmission and distribution network owners and service providers, retailers and customers. Specific Code chapters deal with registration of participants, rules for the operation of the central dispatch process and spot market, security arrangements, network connection access including network pricing, and the administration of the code itself.

A spot price is calculated for electricity for each half-hour during the day and is the clearing price to match supply and demand. Although suppliers make offers 24 hours ahead, these offers may be revised until a short period before the real time auction. Given the final set of offers and bids for the real time market, a one period Optimal Power Flow is performed to determine the least -cost pattern of generation. The advantage of this approach is that it requires suppliers to self-commit capacity to the market, and as a result, it avoids the computational complexity of solving a unit commitment problem for a day-ahead market. This eliminates the possibility for one type of gaming that has been a chronic problem in the UK market. It is a major step of faith to leave the commitment of capacity to market forces in the spot market. Some regulators in the USA have been reluctant to take this step. The concern is that the reliability of the system will be threatened if some form of market for capacity is not established. The price paid in the Australian market is, literally, the acceptance of high prices when the total level of load is close to the available capacity. A high price in the spot market (even a forecasted high price for energy) gets suppliers motivated and back to work getting generation available. Compared to a few years ago, capacity factors for inexpensive sources of generation in Australia have increased to levels that far exceed the established operating practices under regulation. In addition, proposals to build new capacity have been submitted in regions that have high prices.

In spite of the low competitive prices and the high reliability of the market in Australia, the tradition for planning in the former state-owned system has not been lost. Hence, there are formal procedures to check that installed capacity in the future will be sufficient to meet projected load. Intervention in the market by regulators is allowed, but any additional capacity ordered by regulators must be priced at the existing price cap, which is presently $\$ 5,000 / \mathrm{MWh}$. The rationale is that market forces will not operate effectively if there is any threat of intervention by regulators at a price lower than the cap. The contrast between the market structures in Australia and New England, for example, is striking. The price cap in Australia is high and there is no formal capacity market. In New England, the price cap is low and there is a cumbersome process for adding capacity that probably discriminates unfairly against new entrants."

"Tim Mount, Cornell University. 
In general, all electricity must be traded through the spot market. Generators and retailers also trade in hedge contracts outside the pool to hedge the fluctuations in the spot prices and essentially contract at a fixed cost. These hedge contracts are financial instruments and do not affect the operation of the power system in balancing supply and demand in the pool. Western Australia and the Northern Territory will not be directly involved in the NEM because of the long distances involved.

The responsibilities of NEMMCO are:

\# Establish and conduct the wholesale electricity market.

\# Coordinate power system planning for the market.

\# Manage the power system to balance supply and demand.

\# Maintain system security.

\# Administer the spot market.

\# Contract the necessary ancillary services to operate the power system.

\# Coordinate power system planning in conjunction with Network Service Providers and in consultation with Market Participants.

Historically, each state developed its own transmission network. The entities that own or lease and operate the different electricity networks are called Network Service Providers. The National Code spells out the rules, by which a Network Service Provider must plan for the expansion of their network, operate their network and provide access to a party seeking connection either as a generator or customer. Market participants are required to pay their local Network Service Provider a connection charge and a use of system charge. In return for the network charge, the participant is entitled to receive a level of network service specified in the Code. The network charges are to provide sufficient incentives for the economically efficient expansion and maintenance of the transmission and distribution networks. 
NEMMCO calculates a spot market price at a reference node in each of four regions. The electrical losses between regions are called the inter-regional loss factor. The inter-regional loss factor is used to adjust the offer and bid prices when determining which generators are dispatched to meet electricity demand. In the central dispatch process, intra-regional loss factors are also used to adjust offer and bid prices in the dispatch of generators to meet electricity demand.

A customer can choose to buy electricity in the retail market from one of several competing retailers, or if they decide to purchase directly from the wholesale market, they will need to register with NEMMCO as a Market Customer. In each area, there is a planned schedule of customer size that determines when a customer with a particular load size qualifies to purchase directly from the wholesale market. For example, in New South Wales, a customer can qualify to purchase from the wholesale market in accordance with the following schedule:

\# Above $5 \mathrm{MW}$ or $40 \mathrm{GWh}$ per year

\# $\quad$ Above $1 \mathrm{MW}$ or $4 \mathrm{GWh}$ per year

\# Above $750 \mathrm{MWh}$ per year

\# Above $160 \mathrm{MWh}$ per year

\# $\quad$ All Customers
October 1996 (47 sites)

April 1997 (660 sites)

July 1997 (3,500 sites)

July $1998(10,800$ sites $)$

January $2001(2,700,000$ sites $)$

Entering the wholesale market entails transaction and other costs to the customer that are additional to those faced in the retail market. First, SCADA metering needs to be installed. This measures electricity consumption at the customer's premises and feeds the data into the Energy Management System and Scheduling, Pricing, and Dispatch (SPD) used by NEMMCO in real time (the Independent System Operator). Second, each wholesale customer needs to establish a trading team that monitors the spot price and submits the customer's bids, and a settlements system that is compatible with the NEM settlements system. Third, wholesale customers may also need to enter hedging contracts to offset some their financial risks. Finally, wholesale customers may wish to install load-switching equipment and modify their production processes. All of these costs need to be weighed against the alternative cost of purchasing electricity from a retail company. This retail option is still the simplest and cheapest for many customers - they don't have to know how the market operates and what drives the price; or how to hedge risks. 
At present, there is only one large customer who has elected to enter the NEM. The company is in the food processing industry and consumes a large quantity of electricity for refrigeration and freezing. The company finds it profitable to switch off some of its refrigerators and transfer contents to the others when prices are expected to be high. Other industrial customers cannot operate in such a way because it is too disruptive to their production process. For example, smelter pots cannot currently be turned off with molten metal in them -- the costs of cleaning out the pots is usually greater than the benefit from reduced electricity consumption. The number of wholesale customers is expected to increase as the costs of participating in the wholesale market fall. In future, changes in the structure and rules of the NEM may induce greater demand-side participation by large and small customers."

Average electricity prices in NSW have fallen by $22 \%$ since 1992 . Residential prices have fallen by $10 \%$ and business prices have fallen by $30 \%$. Significant savings have been secured by the customer who has qualified to purchase from the wholesale market."

\section{Observations}

Australia has a system where ancillary services are contracted rather than made part of the market, although they may be made part of the market in the future. They also have a relatively simplified bidding process, and stringent codes on how the market is to be operated that apply uniformly across the various regions. Available reports indicate that the market is working well in reducing costs, and there does not appear to be excessive market power or gaming. The market in Australia is highly competitive because the government of Victoria set the standard by selling each state-owned power plant to a different private company.

\section{MIDWEST PRICE SPIKES}

In the Summer of 1998 and again in the Summer of 1999 , power prices rose to $\$ 7000 / \mathrm{MWH}$ and $\$ 9000 / \mathrm{MWH}$ for several hours during several consecutive days throughout many Midwestern states. Clearly these are not prices that relate easily to marginal production costs. Was this a system security concern? Was it a market failure? It could be both, either, or neither.

"Information provided by R. Pritchard and T. Gregan of NEMMCO.

\#"Pricing for Electricity Networks and Retail Supply," Issues Paper, Independent Pricing and Regulatory Tribunal of NSW. 
The fundamental physical problem was that, for a number of market participants, generation was not sufficient to meet load and the bulk supply market was thin. As will be discussed later, loads themselves were not allowed to see the real-time prices. Consequently, there was no demand side response available. The result was extremely high prices. It is reasonable to view this as a system that functioned essentially as designed. It is also reasonable to view this as a market failure since a market with no elasticity of demand is only half a market.

The extent to which these events were, and future events are, a security concern depends on how the system operators respond to market and political pressure. If the system operators maintain reliability reserves, even if this must be done at the expense of firm load, then system security can be maintained." If, on the other hand, system operators deploy contingency reserves to provide energy and operate the system with contingency reserves reduced or eliminated then security is threatened seriously. Unfortunately it is difficult to monitor how system operators respond to this type of event. Hence it is difficult to assess the extent to which security is compromised.

*An additional option is available. Generation that would otherwise be used to provide contingency reserves can be deployed to produce energy if appropriately curtailable load can be deployed to replace it as contingency reserves. 


\section{LOAD AS A BULK POWER SYSTEM RELIABILITY RESOURCE}

Historically, utilities have treated loads as unable or unwilling to modify behavior in response to price signals." This resulted in the revenue metering and tariff system we have today that does not allow for demand response. Even when energy prices hit $\$ 7000 / \mathrm{MWH}$ as they did in the Midwest in the Summer of 1998 , or $\$ 9000 / \mathrm{MWH}$ as they did in the same region in the Summer of 1999, customers received no price signal indicating that they should curtail consumption. They also received no economic reward for responding to moral appeals to reduce consumption. With loads barred from the real-time energy markets it is not a surprise that load response is even less developed as a resource for selling ancillary services.

For the competitive system to work, end users of electricity need to see prices that reflect the cost consequences of their consumption patterns. This is fundamental to our idea of what a market is, and without some demand elasticity, it's rather misguided to think bulk power markets can work well.

The perception that loads can not or will not respond is so pervasive that regulations, policies, and standards generally do not allow loads to participate in energy and ancillary service markets. Advances in metering, communications, and control technologies are eliminating any technical justification for such restrictions. If these obstacles can be overcome there is high probability that loads will become active participants in both the real-time energy and ancillary service markets. " Because of the high potential for significant impact at relatively low cost and in a relatively short time if the perception of unresponsive load can be changed we devote what would otherwise be an inordinate amount of this paper discussing the issue.

We have received interesting anecdotal evidence of unconventional load response to high prices from one customer that did receive the price signal. A utility in the south reportedly

"Though we focus on loads in this section the obstacles and benefits are essentially the same for distributed generation.

\#"Load A Resource in Providing Ancillary Service Markets", Brendan Kirby, Eric Hurst, American Power Conference, April 1999. 
dramatically cut the lighting in its office tower in order to increase sales into the Midwest market, not in response to any shortage on their own system.

Beyond a fairness argument that all loads should be allowed to participate in markets, having loads participate as suppliers, as well as consumers, of electricity services improves resource utilization. Ancillary services consume generating capacity. When loads provide these reserves, generating capacity is freed up to do what it was designed for, i.e., generate electricity.

Loads will probably respond more quickly to control-center requests than large generators because the load response is composed of many small resources. This will likely more than overcome the communications and control delays associated with their greater numbers. With an ever increasing number of loads utilizing energy management systems for internal reasons the marginal cost of response is low.

Loads should be a more reliable supplier of ancillary services than conventional generators. Because each load will generally be supplying a smaller fraction of the total system requirement for each service, the failure of a single resource is less important. Just as a system with ten 100-MW power plants requires less contingency reserves than one with a single 1000-MW plant so too a system that utilizes a large aggregation of loads as a resource to supply reserves will require less redundancy in the basic resource than one that carries all of its reserves on a few large generators. There can still be common-mode failures in the facilities of the aggregator, but it is easier and cheaper to install redundancy in this portion of the system than with an entire 1000-MW plant.

\section{LOCAL VS CENTRAL CONTROL}

Load control has been and is currently used in a number of locations. * Some implementations have been successful but the idea has not been universally adopted. This is at least partly because of traditional rate structures, which provide little flexibility to customers. The customer must agree up front to be subject to utility control, usually for a year or more. There is no ability to enter and leave the market as the customer's economic conditions change. The customer often gets paid a flat fee independent of how or if the resource is actually used. This provides little flexibility for the load and little incentive to actually perform.

*North American Electric Reliability Council, NERC Operating Manual, Princeton, New Jersey, December 1997. 
Similarly, the costs of peaking generation or peak reserves are typically spread over an entire season or year. Charges (both operating and capital) are not assigned exclusively to the hours when the generation or reserves are required. Assigning the costs to the hours when they are needed would result in much higher prices for those services during specific hours (and lower prices at other times). Under either good economic regulation or a truly competitive market, the result would be the same total revenue collection (that is required to pay for the resource). Providing a price signal that accurately reflects the real-time cost to provide the service will encourage all suppliers, loads and generators, to offer supply when it is needed most.

While automatic deployment is necessary when selling some reserves, it is often important to allow the load to decide when it will participate and when it will not. Just as the price of hourly energy and each of the ancillary services vary, so do customer economics. For many customers there are times when less flexibility exists and the load cannot be reduced without high costs being incurred. These times are often independent of anything happening on the power system and are therefore unrelated to the price of the service. For example, for the right price, a residential customer might be willing to automatically curtail air-conditioning use for 30 minutes to supply contingency reserves. This same customer would probably be unwilling to curtail use at almost any price on the evening when s/he was holding a dinner party, however. Similar restrictions might apply for an industrial customer such as a continuous chemical processing plant while it is taking a monthly inventory and needs a stable process. In both cases the customer choice not to participate is unrelated to the utility economics; neither load is trying to avoid providing the service when it is highest in value. In fact, the chemical plant may intentionally select times for its inventory when the power system is not stressed, such as at night or on weekends. It would do this not because of a concern for the power system but because that may be a time when the chemical process is stable as well due to reduced activity at the chemical plant.

The utility needs information about which loads will be supplying services ahead of time. The load must declare that its availability before it enters or leaves the market. Perhaps this declaration would be one day in advance for the following 24 hours. Both the utility and the load will need the ability to change the availability on shorter notice, perhaps with economic consequences. A load that experiences technical difficulties and is suddenly incapable of supplying the service must be able to leave the market. Conversely, if the power system finds itself unexpectedly short of reserves it will need to be able to call for additional reserves quickly, perhaps by raising the current price. Indeed, this is how the day-ahead, hour-ahead and real-time markets are intended to operate in California's competitive bulk-power system.

It is critical to avoid providing an incentive for a resource (either load or generation) to declare itself available when it is not (as is done in the United Kingdom). Equipment failures are inevitable but service providers should have an incentive to maintain the reliability of their 
resources. They should never find it profitable to sell a service that they know they cannot deliver.

\section{LOAD ECONOMIC DECISION PROCESS}

In competitive bulk-power markets, customers will have many choices with respect to their use of electricity and their payment for electricity services. In the context of this discussion, they can choose to participate in hourly markets and face spot prices that can vary widely in response to supply/demand relationships. Alternatively, they can sell reserve services (options) as discussed below. Decisions on whether to participate in spot markets or sell reserves will be based on the customer's flexibility in modifying its electricity use (in particular, its fixed and variable costs to modify its electricity use in real time), the prices of energy and reserve services, and the frequency with which outages occur.

For example, higher reserve prices and less frequent outages will lead customers to sell reserve services, forgoing opportunities to reduce consumption at times of high spot electricity prices. On the other hand, increasing flexibility (i.e., declining cost) in modifying electricity use will lead to more decisions to participate in spot energy markets.

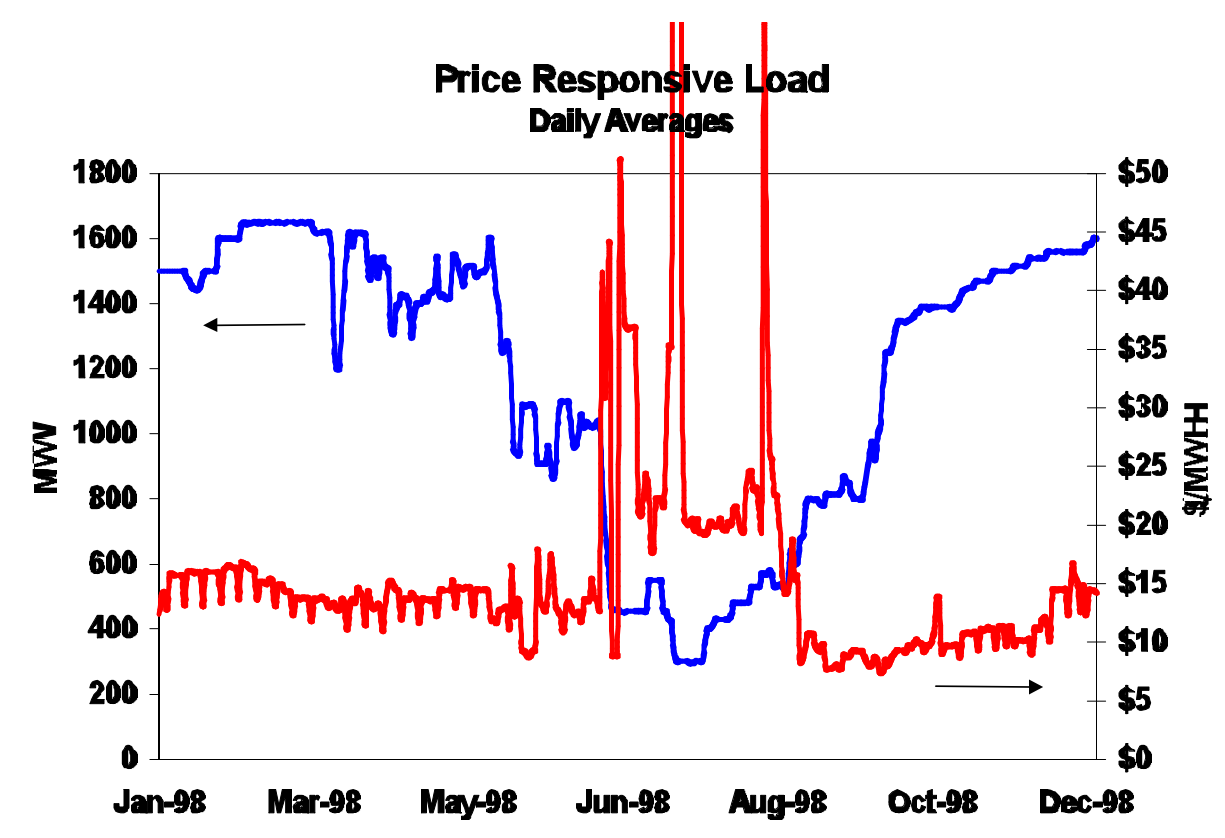

Fig. 2. This load responds to real-time price signals based upon the ever changing power price and the changing conditions within the customers process. 


\section{MARKETS LOADS MAY WANT TO PARTICIPATE IN}

Loads with the capability to control consumption way wish to participate in the hourly energy market. An ability to notify the load of the price for the coming hour is required as is metering capability that can record hourly consumption.

Participation in markets for reliability services imposes additional requirements. The owner of a load, in cooperation with an aggregator and the system operator, would determine the portion of the load that could provide the service. Metering, communication, and control requirements would then be established.

Looking first at the services required to restore the generation/load balance after a contingency, Supplemental Reserve is a likely candidate for many loads. The resource must fully respond within 10 minutes of the contingency. " Response must be maintained for an additional 20 minutes, i.e., until 30 minutes after the contingency. This is a short interruption that many customers may find acceptable. Candidates include water pumping, building temperature control, water heaters, and air compressors. Anything that inherently has some storage in the process, or any process for which storage can be readily added is a good candidate.

The system operator takes some of the 10 minutes to recognize the contingency and to call for response. The aggregator's communications process will consume some time. This leaves a few minutes for the load to respond.

Obviously, the load itself must be consuming power for it to curtail consumption during a contingency. Many candidate loads cycle as they provide service (e.g., hot water heaters). Since individual loads do not cycle together, the aggregation will always have some load available for curtailment. The aggregation has to be accurately characterized to know how much reserve is available at any time. Individual loads also have to be controlled after the reserve is released to prevent them from all returning to service simultaneously.

*Specific timing requirements for each service vary from region to region. The requirements referenced here are from NERC (1999) Draft Policy 10. 
Frequency Responsive Spinning Reserve is both easier and more difficult for loads to provide. Because the service responds to system frequency, each load has the triggering signal available at all times. The service only has to be provided until it is replaced by Supplemental Reserve, 10 minutes, creating a shorter interruption. Full response is required within 10 seconds, however, which may make it harder for some loads to provide. Having each load in an aggregation responding at slightly different frequencies could create a typical generator droop characteristic.

Frequency Responsive and Supplemental Reserves restore the system's generation/load balance and maintain it for 30 minutes. Thirty minutes after a contingency occurs the customer that was receiving the lost generation is responsible for making other arrangements or curtailing its load. The Backup Supply Plan is a pre-arrangement that tells the system operator how to proceed for each load's loss of primary supply. Some loads may find it attractive to provide Backup Supply for other loads. The 30-minute warning provides time for communications and for the curtailing load to take actions to reduce its own costs.

Loads may also wish to participate in maintaining the generation and load balance during normal operations, though this seems less likely. A load or aggregation of loads could provide Load Following by cycling their daily operations in response to direct MW commands from the system operator or by responding to short-term price signals.

Regulation is the least likely of the generation/load balancing services for a load to provide. It is possible, however, that loads with variable speed drives (e.g., water pumping) could accept AGC signals from the system operator. Municipal water pumping accounts for approximately $1 \%$ of national electricity consumption, providing potentially significant sources of load-based regulation or other ancillary services.

\section{CERTIFICATION AND AGGREGATION}

Most of the generators on a typical power system are relatively large and expensive. It is reasonable for the system operator to monitor unit output and bus voltage every 2 to 8 seconds. The amount of data and the expense per MW are both reasonable. When the operator calls for response the response can be monitored in real time.

Providing the same information from hundreds or thousands of individual resources would be prohibitively expensive and would provide an overwhelming amount of data that could not be managed in real time. An alternative to real-time monitoring of each individual resource exists. Loads could be certified, either individually or in aggregation, for the provision of each 
ancillary service. Certification would consist of exercising the resource under controlled conditions to determine the reliable response.29 Testing of the contingency reserves, for example, would not be announced to the resource. The response would be measured on control-area metering. Periodic testing would monitor continued capability. Recording meters at each resource could also be audited to verify performance for both actual events and tests.

The major objection often voiced to customer supply of ancillary services is that the system operator cannot deal with the large number of individual resources and that the communications requirements would be overwhelming. These are valid concerns but ones that can be addressed. Aggregators can provide a genuinely valuable function here. By handling the communications with a large number of loads they can present the system operator with a single point of contact for a reasonable amount of capacity, similar to the system operator's interface with generating resources. The aggregator can also be an interpreter between the electrical system and customers. The system operator is not interested in learning the details and concerns of each customer. Similarly, customers are in businesses of their own and have neither the time nor the interest in learning all about the power system. The aggregator can bridge this gap, creating a valuable resource in the process.

Communications are inherently different with an aggregation of resources than with a single entity. It is not currently practical to collect data from thousands of individual loads at the 2 to 8 second scan rate most utility data collection systems operate at. It is practical, however, to send instructions to those loads as fast as necessary. That is because it is the same signal broadcast to all loads for response.

\section{BARRIERS TO SUCCESS}

Loads should be encouraged to actively participate in real-time energy markets and provide several of the energy-balancing ancillary services because of the reliability and commercial benefits provided by expanded supplies of these resources. Artificial barriers to the entry of customers into these markets should be removed. The customers themselves will have to determine their economic costs and benefits to see if and when they will participate. Loads must be given the flexibility to respond to their own economic constraints.

Technical problems associated with the need to aggregate many individual loads to achieve a resource of sufficient size to be useful can be overcome. This may be one of the areas where load aggregators can play a genuinely useful role. An aggregator can relieve the system operator of the burden of dealing with an excessive number of individual resources while still providing the required response. Similarly, the high communications burden associated with a large number of resources can be alleviated by broadcasting control signals to the resources. 
Rigorous certification, coupled with post-event meter audits, can substitute for real-time monitoring of each resource. 


\section{SPECIAL R\&D NEEDS TO FACILITATE RELIABILITY AND BULK POWER MARKETS}

Successful market systems require a clear and well defined market code of conduct that is applied uniformly across a large region. Such a code cannot be developed without research to support the development of effective market functional criteria. These criteria span an array of needs from the development of standards for interconnection of distributed resources and for bulk system operations to the development of metrics for individual service provision and overall market performance. Research into market structures themselves is also required for both generation and transmission. Secondly, technology is needed to facilitate the flexibility required as generation and transmission markets diverge. There are a number of unresolved issues at present for the funding and planning of transmission grid expansion.

\section{STANDARDS AND METRICS}

You cannot sell what you can not measure. Market based systems have a much greater need to define and quantify interactions than the vertically integrated industry of the past had.

\section{Ancillary Services}

Individual ancillary services must be defined in such a way that they contribute to the reliable operation of the system and such that their provision can be monitored, quantified, and paid for. Ancillary services must be defined in a way that is technology independent; the definitions should focus on the desired results rather than upon the supplying technology. To the maximum extent possible, these standards should be uniform and national in order to encourage market participation by as broad a group of resources as possible.

\section{Interconnection Standards}

Interconnection standards for distributed generation must meet the safety and reliability needs of the system while also encouraging the availability of additional resources. Interconnection standards must avoid any actual or perceived use as a barrier to competition. To the maximum 
extent possible these standards should also be national in order to encourage market participation by as broad a group of resources as possible.

\section{Metrics}

Metrics should be developed to quantify the behavior of overall markets. There is currently no way to meaningfully quantitatively compare the California and PJM markets, for example. Any comparison must be done on a national level. Progress is difficult without comparison metrics for such fundamental qualities as overall market structure.

Research should focus on defining the fundamental requirements for each ancillary service and on interconnection requirements. That research should then be used to develop interconnection and service standards. There are new market "practices" occurring in some regions, that, under a clearer code of conduct, might well be termed fraudulent. One of these practices is to "overlook" the simultaneous sale of capacity into multiple markets and then accept disproportional low penalties when the practice is discovered.

This is an important area for DOE to focus on. The ongoing work and debate in this area is naturally dominated by parties with vested commercial interests. DOE brings an important nonpartisan perspective that can advance the public good.

\section{MARKET STRUCTURE}

Significant research is required in order to support reliable integrated operation of the electric grid under restructuring where numerous competitive entities interact, each pursuing their individual self interest. The code of conduct that governs how the market system is designed and operated is critical to assure that the overall result is a power system that is reliable, economic, and adaptable to changing needs. This research should move forward in four distinct phases.

\section{Theoretical Work}

Some authors continue to advance theoretical models for alternative market structures (Nodal, Zonal, etc.). "Best candidate" models should be selected. These models must be expressed in a common framework so that the differences, unique features and commonalties can be understood. The expression of the models could be in a flowchart graphical format. 


\section{Simulation}

The operations of single markets and the interactions of multiple energy and ancillary service markets should be simulated under a matrix of market structures and conditions. This can help compare overall market structures. It should also be used to test specific rule sets for unintended results from market design changes.

\section{Experimental Economics}

Market interactions are often too complex to capture fully with direct simulation, especially since market participation is inherently a human activity. The strong coupling between the energy and ancillary service markets along with the temporal coupling that results from unit commitment constraints make this problem especially difficult. Experimental economics should be used to test market structures and market rule sets with human participants in a set of scenarios. Research concerning the general market structure (concurrent vs sequential markets, for example) should be conducted. Research concerning specific, detailed rule changes should be conducted as well.

\section{Field Experiments}

With several market structures in operation, and additional ones being proposed, each should be treated as a field experiment. Performance should be studied and compared on a national basis. As rule changes are implemented these should be studied as well. Results should be folded back into the simulation and experimental economics work to refine those efforts.

Research is also needed to see how markets impact transmission congestion. Underlying transactions should be examined to see how they are impacting transmission use. We are already receiving requests for DOE to perform this research.

Research trials are also needed at the small industrial and even residential level for wholesale market participation. Case studies could be performed and showcase demonstrations developed to assist in consumer understanding of how the system works and what savings are available. Alternate market interface platforms and methods would be developed and tested.

\section{GRID EXPANSION}


Although the ISOs have protocols in place for planning grid improvements, there are competing market interests. Grid expansion can obviate the need for new generation, and new generation installed in the correct location can reduce or eliminate the need or transmission enhancement. Because of this dilemma, and because transmission expansion is so difficult to plan, certify and permit in many parts of the country, many transmission expansion issues remain to be resolved. A cohesive national strategy is needed to address this situation, because a strong transmission system is the backbone on which the new market systems can be built. Rotating blackouts were experienced last summer in the PJM region, and there are chronic areas of congestion in the California ISO. Both ISOs have detailed protocols, as discussed in Section 5, for planning transmission enhancement, but a uniform method for quantifying and allocating the benefits of transmission expansion is not available. Research is needed to develop a theoretical model for transmission expansion as a service to the customer.

\section{TECHNOLOGY NEEDS}

Any technology that increases the system operator's flexibility to observe or control the power system or that increases the throughput of the transmission system is useful in supporting market development. This includes transmission technologies themselves but also includes sensors, communications, and controls. Technologies that offer additional options in managing congestion or in supplying ancillary services decrease market power and reduce the need for governmental regulation. Examples of important technologies include:

! Distributed resources (load and generation) offer additional sources of energy and ancillary services. They can be used to alleviate transmission congestion. Distributed resources are instrumental in alleviating congestion, but the mass of the electricity customers are not currently seeing real-time price signals, and small generators are often finding connections to be nearly impossible. The use of distributed generation, while promising because of the environmental friendliness of some of the new generation technologies, has seen little use thus far because of the control complexity and interface flexibility. One of the major grid blackouts that occurred this summer (Delmarva) was made worse by the inability of generation to connect in to the troubled grid when the voltage was so low.

! The Multilevel Converter would be ideal for addressing the problem of control and connection of distributed generation. The Multilevel Converter is a power electronics concept that can be applied at transmission system voltages and currents to marry together systems that are operating at different voltages and frequencies. This capability would be ideal for distributed generation, as it would permit the distributed 
generation to be connected regardless of the grid condition, and it would also provide precise control over the voltage, phase angle and frequency, something that would be incredibly complex using today's technology. The multilevel converter would facilitate remote control of distributed generation.

! Inexpensive supervisory control and data acquisition. For large-scale load participation in wholesale markets, data telemetering must be low cost so that small loads, even residential, can participate. It may be possible to use a computer network interface on existing phone lines, pagers, or other technologies for customers to monitor real time prices, and then program price levels where they may wish to reduce consumption. The network interface could also be incorporated into energy management systems for large buildings, and could be used for larger loads that are controlled as ancillary service providers. There also may be a need for load aggregators to lump together small loads into blocks that are meaningful to the system operator.

! Real time system control. System operator tools to facilitate observing and controlling the power system including improvements in state estimation, data visualization, and forecasting.

! Superconducting cable. Increases transmission capability and reduces congestion.

! $\quad$ FACTS (Flexible Alternating Current Transmission System). Alleviates transmission congestion without constraining generation markets. Advanced semiconductor devices such as diamond or silicon carbide may dramatically lower the cost of FACTS devices and DC line terminals. This would not only make control of the transmission system easier, but would also facilitate private investment in transmission constraint relief.

! WAMS (Wide Area Measurement System). Allows greater throughput on the transmission system.

Research in all three areas, standards and metrics, market structure, and technology are appropriate concerns for federal funding. Benefits accrue to the community as a whole yet it is difficult or impossible for individuals to profit from advancing the state of knowledge in these areas. DOE is an appropriate sponsor for this research because it is energy related and outside the scope of other organizations. 


\section{CONCLUDING REMARKS}

The electric utility industry is going through major changes that are requiring significant shifts in operating paradigms, but the future is quite exciting. There is the potential that electric power is going to be much less expensive, and that many industries, and perhaps even households, will have the opportunity to become players in the real time energy and ancillary service markets.

Energy markets typically operate in hourly or half-hourly increments. This interval may shrink further as technology enables the market response to improve. Ancillary services are used for a variety of needs such as balancing load and generation on a shorter time frame than energy markets operate in and assuring system security (assuring that the system can withstand sudden disturbances). Ancillary services have typically been provided by generators under control of the system operator. Markets can be created for ancillary services as they are for basic generation. A range of possibilities exists for market based ancillary service provision, as exists in structuring basic energy markets. The system operator can use markets to procure the services themselves through sequential or simultaneous markets. Alternatively, the system operator can centrally optimize the provision of all ancillary services from a pool of resources whose controllable capability is procured through a market mechanism. In either event, the specific services must be far better defined than they have been in the past. Metrics are needed to measure provision and consumption of the services. You cannot buy and sell what you can not measure.

Transmission presents a greater challenge still. The inability to control flows over individual elements makes the transmission system fundamentally a community resource. Transmission congestion can block low priced generation from reaching high priced markets. But it is difficult to entice private investment in resources that benefit both the investor and its competitors. Location based pricing can allocate scarce transmission resources and can illuminate transmission investment decisions but it does not necessarily provide sufficient revenue to pay for transmission expansion. Investment decisions then become a community concern. The problem is made worse because of the heavy interaction of transmission and generation. Generation located in the correct spot can compensate for inadequate transmission. Similarly, generation inadequacy in one location can be eliminated through the addition of transmission. Conversely, generation that locates in a high-priced region and is doing well commercially can be driven out of business if new transmission links the region 
with a low cost area. There is no clear institutional answer to this problem. It is clear that new planning tools are needed that accommodate private and public investment decisions.

There is a need for research on a number of fronts to ensure that the transition to an open market is made without jeopardy to system security or adequacy. The process of transition thus far, with the price spikes and rotating blackouts in the US, and the wholesale restructuring of the new system in the UK, show us that the transition will be complicated, and that the potential for mistakes is real. 